\title{
Recomendações para o Desenvolvimento de Softwares Voltados para Crianças com Transtorno do Espectro Autista
}

\section{Software Development Recommendation for Children with Autism Spectrum Disorder}

\author{
Heloise Cristini Magaton \\ Universidade Tecnológica Federal do Paraná \\ helomagaton@gmail.com
}

\author{
Silvia Amélia Bim \\ Universidade Tecnológica Federal do Paraná \\ sabim@utfpr.edu.br
}

\begin{abstract}
Resumo
O Transtorno do Espectro Autista (TEA) é um distúrbio do desenvolvimento que se caracteriza por alterações presentes desde idade muito precoce, com impactos múltiplos e variáveis em áreas relevantes do desenvolvimento humano, como comunicação, interação social, aprendizado e capacidade de adaptação. Estudos comprovam que crianças diagnosticadas com TEA gostam de tecnologia, como qualquer outra criança, sendo usada como uma ferramenta no auxílio ao tratamento deste transtorno. Essa pesquisa apresenta uma revisão de recomendações para o desenvolvimento de softwares para o público com TEA a partir de uma pesquisa bibliográfica e de um estudo de campo. Tal estudo consistiu na observação da interação de crianças TEA com a tecnologia em uma clínica especializada no tratamento deste transtorno e aplicação de questionários com profissionais especializados em TEA e responsáveis das crianças com TEA participantes das observações. A análise dos resultados confirma 12 recomendações encontradas na pesquisa bibliográfica e propõe 6 novas recomendações, as quais poderão ser usadas no desenvolvimento de softwares voltados para o público com TEA.
\end{abstract}

Palavras-Chave: <Transtorno do Espectro Autista, Softwares, Aplicações, Recomendações, Design, Desenvolvimento, Autismo >

\begin{abstract}
The Autism Spectrum Disorder (ASD) is a development disturb which is characterized by alterations that are present since early ages, with multiples and variables impacts in relevant areas from human development, as communication, social interaction, learning and adaptation capacity. Studies show that children diagnosed with ASD like technology as any other children, and it is used as a helping tool in the treatment of this disorder. This research brings up a recommendation review for ASD children software development from bibliographical research and from a field research. The field research consisted in ASD children observations interacting with technology at a specialized clinic in ASD treatment and questionnaires application to specialized professionals and ASD children responsible. The result analyzes confirms 12 recommendations found in bibliographical research and proposes 6 new recommendation, which can be used in software development for ASD children.
\end{abstract}

Keywords: <Autism Spectrum Disorder, Software, Applications, Recommendation, Design, Development, Autism.>

Cite as: Magaton, H.C. \& Bim, S.A.(2019). Software Development Recommendation for Children with Autism Spectrum Disorder (Recomendações para o Desenvolvimento de Softwares Voltados para Crianças com Transtorno do Espectro Autista). Brazilian Journal of Computers in Education (Revista Brasileira de Informática na Educação - RBIE), 27(2), 112-139. DOI: 10.5753/RBIE.2019.27.02.112 


\section{Introdução}

De acordo com a Convenção sobre os Direitos das Pessoas com Deficiência (ONU/2007) e a Lei 5.296 de Dezembro/2004 ${ }^{1}$ a acessibilidade deve ser oferecida a todos ou ao maior número possível de usuários em situações limitantes. A tecnologia tem auxiliado em parte deste processo de inclusão através, por exemplo, de aplicativos mobile e sistemas computacionais interativos. O uso destes aplicativos mobile pode proporcionar a este grupo de pessoas a realização de forma mais autônoma de algumas atividades de educação, entretenimento, interação, comunicação, entre outras. Consequentemente, possibilitando uma maior integração destas pessoas à sociedade (Baranauskas, Souza \& Pereira, 2014).

Nas últimas décadas tem se observado um grande crescimento no desenvolvimento de softwares focados em ajudar e educar crianças com Transtorno do Espectro Autista (TEA), sendo estes desenhados para diferentes plataformas, como tablets, smartphones, computadores e outros, os quais visam auxiliar na alfabetização (Farias, Silva \& Cunha, 2014; Pantoja, Sousa, \& de Araújo Júnior, 2018), na aquisição de vocabulário (Cunha, 2011), e na comunicação, organização, e interação de indivíduos com TEA (Piconi \& Tanaka, 2003; Ribeiro, Braz, Silva \& Raposo, 2013; Neto, Rufino, Nakamoto, Palis, \& Beira, 2017). De acordo com algumas pesquisas, a tecnologia mostra efeitos positivos e benéficos em crianças diagnosticadas com TEA (Putnam \& Chong, 2008; Goldsmith \& LeBlanc, 2004). Embora existam poucos guias disponíveis na literatura para conduzir o desenvolvimento de tecnologias para este grupo, envolver usuários TEA durante todo o processo de design do software ainda pode ser desafiador, pois todo o processo será afetado por suas particularidades (Millen, Edlin-White \& Cobb, 2010).

Estudos de Millen et al. (2010) identificam algumas dificuldades encontradas em envolver crianças do grupo TEA no processo de design de um software. Algumas das dificuldades descritas na pesquisa são: a linguagem limitada, a qual pode gerar dificuldades na comunicação do usuário em reportar ideias e formular suas opiniões, e pouca habilidade para a imaginação, a qual poderia causar potenciais dificuldades quando protótipos de baixa fidelidade são usados, pois requer que o usuário use sua imaginação para visualizar o produto final. Portanto, por ser difícil e tomar muito tempo para o levantamento de requisitos durante um processo de design focado nos usuários, os autores Millen et al. (2010) afirmam a importância em estabelecer recomendações para o desenvolvimento de software voltado para o público TEA.

Também se considera relevante que para desenvolver tecnologias condizentes com as necessidades de indivíduos com limitações cognitivas é necessário conhecer como esse público as utiliza e de que modo eles são afetados por elas. Diante desse cenário, este artigo revisa trabalhos existentes na literatura que sugerem recomendações para o desenvolvimento de softwares voltados para o público TEA. E através de um experimento realizado com crianças TEA, seus(suas) responsáveis e profissionais especializados no transtorno, procura confirmar as recomendações já existentes e sugerir novas recomendações.

Este artigo está dividido em seis seções, sendo a primeira destinada a introdução, e a segunda a definição de conceitos como o TEA. A terceira seção define a metodologia utilizada para essa pesquisa, contendo um breve panorama sobre a pesquisa bibliográfica e um relato mais detalhado sobre a pesquisa de campo. Na quarta seção são analisados os resultados encontrados durante a pesquisa de campo, e consequentemente na quinta seção é apresentado os resultados obtidos através das análises da pesquisa bibliográfica e pesquisa de campo. E por fim, as considerações são relatadas na sexta e última seção.

\footnotetext{
${ }^{1}$ http://www.planalto.gov.br/ccivil_03/_ato2004-2006/2004/decreto/d5296.htm
} 


\section{Conceitos Básicos: TEA}

O TEA é um distúrbio do desenvolvimento que se caracteriza por alterações presentes desde idade muito precoce, tipicamente antes dos três anos de idade, com impacto múltiplo e variável em áreas relevantes do desenvolvimento humano como as áreas de comunicação, interação social, aprendizado e capacidade de adaptação (Mello, 2001).

Por muitos anos o TEA foi considerado como uma psicose, sendo comum ouvir profissionais se referindo a pessoas diagnosticadas com TEA como esquizofrênicas ou psicóticas, e tendo várias denominações durante os anos. No Manual Diagnóstico e Estatístico de Transtornos Mentais Cinco (DSM-V) (American Psychiatric Association \& Others, 2014) é realizada a fusão dos termos Transtorno Autista, Transtorno de Asperger e Transtorno Global do Desenvolvimento no termo Transtorno do Espectro Autista. Segundo o manual, os sintomas desses transtornos são similares podendo ser classificados em intensidades que variam de leve a grave nos domínios de comunicação social e de comportamentos restritivos e repetitivos. No manual, a intensidade leve é representada pelo nível 1, a moderada pelo nível 2 e a grave pelo nível 3.

Segundo o manual, a incidência do TEA é quatro vezes mais frequente no sexo masculino, e quando diagnosticado em meninas é mais propenso a apresentar deficiência intelectual concomitante. Ainda de acordo com o manual, as frequências relatadas de TEA nos EUA e em outros países, alcançaram 1\% da população. O transtorno se manifesta desde os primeiros dias de vida e os sintomas são reconhecidos no segundo ano de vida (American Psychiatric Association \& Others, 2014).

\section{Métodos}

De modo semelhante às demais pesquisas realizadas para elaboração de recomendações para o desenvolvimento de softwares/hardwares para crianças com TEA, a pesquisa relatada neste artigo é classificada quanto a sua abordagem como qualitativa com amostras pequenas, de natureza aplicada e de cunho exploratório. Os procedimentos utilizados para a realização desta pesquisa foram: pesquisa bibliográfica e pesquisa de campo.

\subsection{Pesquisa Bibliográfica}

A pesquisa bibliográfica primeiramente foi composta por um breve estudo sobre a definição do Transtorno do Espectro Autista e das características dos indivíduos desse grupo. Para a revisão bibliográfica foram realizados estudos de trabalhos já publicados sobre o desenvolvimento de softwares voltados para o público com TEA, em portais como o da ACM, CAPES, Google Scholar e IEEE buscando por palavras chave utilizando os idiomas inglês e português: Autismo, Transtorno do Espectro Autista, Desenvolvimento, Softwares, Recomendações, Design, Aplicativos.

Nesses estudos objetivou-se identificar recomendações de design seguidas para o desenvolvimento de um determinado artefato ou software direcionado para crianças com Transtorno do Espectro Autista. A seguir será relatada algumas pesquisas encontradas na literatura.

Um guia com oito recomendações foi elaborado por Van Rijn e Stappers (2008) baseado em estudos e pesquisas contextuais, como pesquisas com especialistas, e testes com usuários TEA utilizando protótipos. As oito recomendações de design foram elaboradas a partir da construção de um brinquedo, construído por eles mesmos, chamado LINKX, o qual auxilia as crianças a aprenderem suas primeiras 100 palavras, e da avaliação desse brinquedo com um grupo de 3 crianças, de 3 a 5 anos diagnosticadas com TEA. Apesar de Van Rijn e Stappers (2008) terem 
desenvolvido recomendações a partir do desenvolvimento de aplicações que envolvam a construção de algo físico, essas recomendações também podem ser incorporadas ao design de softwares, como Dautenhahn (2000) sugere a seguir.

Para o desenvolvimento do projeto Aurora, Dautenhahn (2000) se baseou em uma série de recomendações de design. O projeto consistiu em investigar como um robô autônomo poderia auxiliar e incentivar as interações sociais dos indivíduos TEA, e a ajudá-los a reconhecer e reproduzir elementos importantes do comportamento social humano, como contato visual, consenso, abordagem, reconhecimento de expressões e emoções etc. A autora em seu texto sugere que algumas recomendações de design que foram utilizadas para a construção do robô também sejam usadas para ambientes virtuais interativos com fins educacionais.

A partir de estudos e pesquisas em escolas irlandesas, com profissionais e responsáveis, Barry, Kehoe e Pitt (2008) trazem uma análise da usabilidade em jogos educacionais voltados para o público TEA. Os autores abordam em sua pesquisa aspectos de softwares educacionais que podem ser problemáticos para os indivíduos TEA. Por exemplo, alguns jogos têm interface não limitada, na qual o usuário pode explorar o mundo do jogo, porém, essa abordagem pode ser problemática para os usuários TEA pois uma das suas principais características é gostar de rotinas e ambientes previsíveis. Outro problema citado pelos autores são as cenas de vídeos, as quais podem lhe causar confusão pois preferem imagens simples. E por último, o som como uma recompensa do jogo pode não soar como uma recompensa se este estiver muito alto e perturbador, indivíduos do grupo TEA na sua maioria são visuais, podendo não reagir bem a certos níveis de sons.

Assim como outros estudos relatados aqui, Millen (2007) apud Millen, EdlinWhite e Cobb (2010) e Edlin-White (2009) apud Millen, Edlin-White e Cobb (2010) identificaram algumas recomendações baseadas em observações e entrevistas em duas escolas especialistas em crianças com Transtorno do Espectro Autista, entrevistas com responsáveis e professores(as) assim como estudos na literatura.

A pesquisa de Millen (2007) apud Millen et al. (2010) contemplou um documento com recomendações de usabilidade, o qual aborda o uso do som, da linguagem, conteúdo e gráfico. A pesquisa de Edlin-White (2009) apud Millen et al. (2010) por sua vez se baseou nas recomendações anteriores e produziu um documento com cinquenta requisitos. A grande quantidade de requisitos levantados se deu devido à grande diversidade de crianças com diferentes graus de TEA e suas características particulares que participaram do estudo.

Britto e Pizzolato (2018) propõe em seu trabalho o projeto GAIA: Guia de Acessibilidade de Interfaces Web com foco em aspectos do Autismo, o qual tem como objetivo prover um conjunto de diretrizes e recomendações de design para a acessibilidade com o intuito de apoiar desenvolvedores de softwares e educadores digitais a entender melhor como desenvolver websites mais adequados às necessidades de crianças com TEA, tendo como foco aplicações baseadas em plataforma Web e/ou dispositivos multitoque. As recomendações foram extraídas através de um processo de revisão de trabalhos publicados, incluindo recomendações internacionais, softwares comerciais ou acadêmicos, gerando um conjunto de 28 recomendações disponibilizadas em um $w_{\text {website }}^{2}$. Também para garantir a utilidade das recomendações, foi realizada uma avaliação piloto remota com profissionais de tecnologia onde eles foram solicitados a realizar uma avaliação de acessibilidade de uma aplicação web utilizando o GAIA, obtendo resultados positivos. As recomendações apresentadas pela pesquisa citada não foram possíveis serem observadas, pois as observações com o público TEA ocorreram anteriormente a essa referência. Porém, algumas

\footnotetext{
${ }^{2}$ http://talitapagani.com/gaia/
} 
recomendações compiladas por Britto e Pizzolato (2018) complementam algumas recomendações dessa pesquisa como pode ser observada na seção 6 .

\subsection{Pesquisa de Campo: Observações}

O estudo de caso realizado nesta pesquisa consistiu na observação de seis crianças com TEA interagindo com oito aplicativos educativos distintos em quatro dias. As observações foram realizadas em uma única instituição com o acompanhamento de oito profissionais e/ou estagiários(as) da área de psicologia. A técnica de observação foi escolhida devido às limitações de comunicação dos indivíduos TEA.

Para análise das observações realizadas foram considerados outros trabalhos sobre avaliações de softwares com a participação do público com TEA (Farias et al., 2014; Piconi \& Tanaka, 2003; Ribeiro et al., 2013), os quais além de observações com crianças com TEA também contaram com a participação de responsáveis e profissionais especializados.

Deste modo, para esta pesquisa também foram aplicados questionários com perguntas abertas, enviados por e-mail, para os(as) profissionais e pais/mães/responsáveis das crianças observadas. O objetivo das perguntas para os(as) profissionais era compreender a dinâmica da clínica e a opinião destes(as) profissionais sobre o uso da tecnologia no processo educacional de crianças com TEA. As perguntas para os(as) responsáveis tinham o objetivo de investigar a relação das crianças com TEA com a tecnologia em outros contextos. As respostas fornecidas nos questionários, dos(as) seis profissionais e dois(duas) responsáveis, também foram consideradas neste trabalho para enriquecer a análise das observações.

As observações ${ }^{3}$ ocorreram em uma clínica brasileira especializada no tratamento do TEA. A clínica atua na área de saúde e educação desde 1992, possuindo um departamento especializado em TEA, atuando na avaliação diagnóstica, atendimento a crianças e adolescentes portadores(as) deste transtorno ${ }^{4}$. Os(as) pacientes TEA frequentam a clínica no período quando não estão na escola regular.

As observações foram realizadas no mês de setembro de 2016, em quatro dias distintos, com intervalo de uma semana entre eles, conforme autorização da coordenadora da clínica. Os testes pilotos das observações, um para cada participante, foi realizado no mês anterior, durante um único dia.

Foram observadas individualmente seis crianças do sexo masculino ${ }^{5}$ com graus de TEA variando do nível 1 a 3 e idades entre 5 e 8 anos, como pode ser observado na Tabela1.

Tabela 1: Tabela que lista os participantes TEA da pesquisa com a sua idade e nível de TEA.

\begin{tabular}{|c|c|c|}
\hline Criança & Idade & Nível de TEA \\
\hline Criança A & 8 & Nível 2 \\
\hline Criança B & 6 & Nível 2 \\
\hline Criança C & 6 & Nível 1 \\
\hline Criança D & 8 & Nível 3 \\
\hline Criança E & 6 & Nível 1 \\
\hline Criança F & 5 & Nível 2 \\
\hline
\end{tabular}

Durante as observações procurou-se interferir o mínimo possível na rotina das crianças. Desse modo, as sessões ocorreram em espaços que os participantes já frequentavam durante o

\footnotetext{
${ }^{3}$ Para mais informações sobre esta pesquisa e observações acessar: http://bit.ly/TCCAutismo.

${ }^{4}$ Informações coletadas no site da clínica: www.selfcenter.com.br.

${ }^{5}$ Infelizmente não foi possível realizar observações com crianças do sexo feminino, frequentadoras da clínica, devido ao alto grau de comprometimento e comorbidades associadas.
} 
período que passam na clínica, acompanhados de uma pessoa familiar a eles, como os(as) psicólogos(as) e estagiários(as) de psicologia da clínica, e utilizando o tablet que frequentemente é usado nos atendimentos.

As observações contaram com sete profissionais (dois homens e cinco mulheres), os quais acompanhavam e mediavam a interação das crianças com um dispositivo tablet. Quatro dos(as) oito profissionais ainda estão em formação, com a graduação em psicologia em andamento.

Na Tabela 2 pode-se observar a relação dos participantes TEA por dia de observação, e também os(as) profissionais que acompanharam cada participante nas sessões de observação. Verifica-se que em alguns dias não foi possível observar as seis crianças. Isto ocorreu devido à ausência dos participantes naqueles dias.

Tabela 2: Relação de participantes TEA e respectivos profissionais em cada dia de observação.

\begin{tabular}{|c|c|c|}
\hline Dias & Participantes & Profissional $^{\text {6 }}$ \\
\hline Teste Piloto & A,B,C,D,E,F & $2,3,1,2,4,4$ \\
\hline Dia 1 & A,B,E,F & $2,3,4,4$ \\
\hline Dia 2 & A,B,C & $2,3,1$ \\
\hline Dia 3 & A,B,C,D,E,F & $2,3,1,2,6,7$ \\
\hline Dia 4 & A,B,C,D,E & $5,2,1,2,6$ \\
\hline
\end{tabular}

Cada observação de cada criança durou trinta minutos, sendo realizada como uma atividade dentro do programa diário elaborado para cada criança. Um termo de consentimento livre e esclarecido foi enviado para os(as) pais/mães/responsáveis solicitando autorização para a realização das sessões de observações.

Os testes pilotos foram realizados para que houvesse a familiarização da observadora com as crianças e o ambiente da clínica e para identificar eventuais ajustes nas sessões. Para os testes pilotos foi requisitado previamente para que o(a) profissional de psicologia que estivesse acompanhando o participante TEA preparasse uma atividade utilizando o tablet e um ou mais aplicativos disponíveis no dispositivo.

No decorrer das sessões dos testes pilotos cada profissional de psicologia conduziu o uso de maneira diferenciada. Alguns(mas) deixaram o uso livre, permitindo que a criança TEA escolhesse seus aplicativos. E outros(as) realizaram o uso guiado em que os(as) profissionais escolhiam os aplicativos. Muitos(as) utilizaram o recurso de troca: se a criança TEA realizasse a atividade proposta, ela posteriormente poderia escolher um aplicativo de sua preferência.

A partir da experiência dos testes pilotos foram feitos alguns ajustes no protocolo de observação. Notou-se uma grande variedade de aplicativos utilizados pelos(as) profissionais da clínica. Tal variedade exigiria maior tempo de análise comparativa das interações e o recurso de tempo da pesquisa era limitado. Desta forma, com o consentimento da coordenação da clínica definiu-se que a observadora sugeriria dois aplicativos para cada dia de observação e que cada um deles seria utilizado pelos seis participantes TEA.

Para que a escolha dos softwares fosse adequada, e respeitasse as características individuais de cada um dos participantes, a observadora coletou previamente informações sobre as habilidades e dificuldades de cada criança TEA. Por exemplo, investigou-se se a criança possuía conhecimento sobre o alfabeto e números e se saberia reconhecer formas geométricas e cores. Ficou a critério dos(as) oito profissionais que aplicariam as atividades se utilizariam ou não o recurso de troca.

\footnotetext{
${ }^{6}$ Os(as) profissionais que acompanharam cada criança estão na ordem em que os participantes foram dispostos na coluna Participantes.
} 
Os aplicativos escolhidos para as observações foram de cunho educacional, desenvolvidos ou não para o público TEA. Os aplicativos não desenvolvidos especificamente para o público TEA foram escolhidos a partir da lista de softwares disponibilizada pela clínica e das sugestões dos(as) profissionais de psicologia do local. Os aplicativos desenvolvidos especificamente para o público TEA foram escolhidos a partir de pesquisas nas lojas de aplicativos e trabalhos já publicados. A escolha destas duas categorias de aplicativos, desenvolvidos e não desenvolvidos para o público TEA, ocorreu pois, de acordo com os(as) profissionais, na maioria das vezes aplicativos não desenvolvidos para o público TEA são utilizados com as crianças durante as atividades na clínica.

Tabela 3: Tabela que relaciona por dia os aplicativos utilizados durante as observações.

\begin{tabular}{|c|c|}
\hline Dia & Aplicativo \\
\hline Teste Piloto & $\begin{array}{c}\text { Color Monster, Galinha Pintadinha, Seasons, } \\
\text { ABC Palavras, Doodlecast, Pepi Bath }\end{array}$ \\
\hline Dia 1 & TP-Shape, ABC Palavras \\
\hline Dia 2 & Seasons, Doodlecast \\
\hline Dia 3 & Aiello, 123 Color \\
\hline Dia 4 & Number Sequence, Color Monsters \\
\hline
\end{tabular}

Na Tabela 3 pode-se observar como os aplicativos foram divididos durante os quatro dias de observações. Como cada sessão de observação durou 30 minutos, foram reservados quinze minutos de interação para cada aplicativo. Alguns dos aplicativos utilizados no teste piloto também foram utilizados nas sessões de observações, como observado na Tabela 3, porém outros não foram utilizados pois deram espaço para os aplicativos desenvolvidos para público TEA. Uma breve descrição dos aplicativos utilizados em cada um dos quatro dias pode ser vista a seguir.

\subsection{Descrição dos Aplicativos}

Nesta seção será apresentada uma breve descrição dos oito aplicativos ${ }^{7}$ utilizados durante as observações realizadas com as crianças TEA. Os seis primeiros aplicativos descritos correspondem aos não desenvolvidos especificamente para o público alvo deste artigo.

\footnotetext{
${ }^{7}$ Os aplicativos utilizados exclusivamente no teste piloto não serão descritos pois a interação dos aplicativos com os participantes TEA não foi analisada.
} 
1.Color Monster ${ }^{8}$ : aplicativo de pareamento de cores. Ao iniciar o aplicativo um avatar interage com a criança pedindo alguma cor para que possa "comer".

Assim o usuário deve arrastar algo até sua boca para que haja interação do avatar, o qual emite sons de incentivo quando o usuário realiza um movimento correto e emite som de reprovação quando usuário erra a cor solicitada pelo avatar. Uma imagem ilustrativa do aplicativo pode ser observada Figura 1.

2.TP-Shapes ${ }^{9}$ : aplicativo de pareamento de formas geométricas. O aplicativo é iniciado com a tela contendo algumas formas geométricas coloridas, a forma da peça a ser pareada naquela interação sem cor com um ponto de interrogação sobre a peça. $\mathrm{O}$ aplicativo emite uma frase com voz feminina como: 'Encontre o Triângulo'.

O aplicativo também emite som para parabenizar quando o usuário acerta a ação e um outro som para quando o usuário comete um erro. Após algumas interações em que o usuário

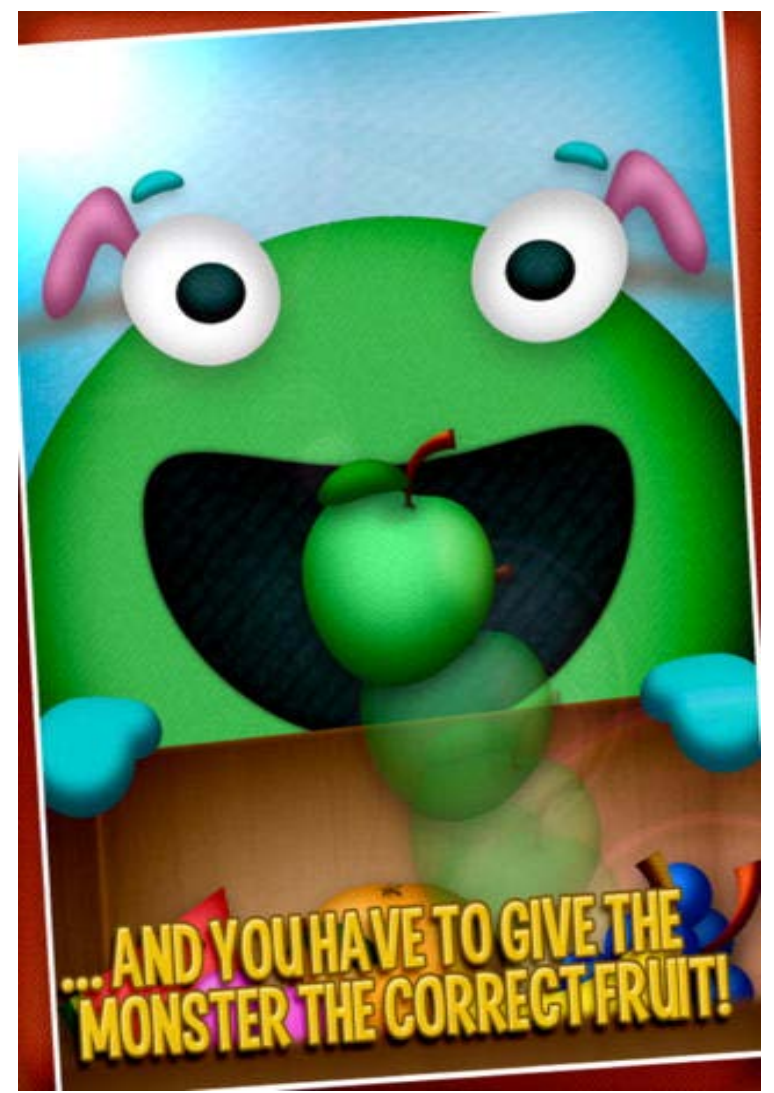

realiza movimentos corretos, o aplicativo oferece uma recompensa que consiste em o usuário poder escolher um adesivo ou completar um quebra-cabeça. Para as observações a opção default do aplicativo foi utilizada: escolha de um adesivo. Após a escolha dos adesivos o aplicativo repete a mesma sequência de formas geométricas já exibidas. Há também uma música de fundo que pode ser desabilitada nas configurações. Entretanto, para as observações foi utilizada a configuração padrão com a música habilitada. O idioma também pode ser configurável. Uma imagem ilustrativa do aplicativo pode ser observada na Figura 2.

\footnotetext{
${ }^{8}$ http://wombiapps.com/apps/color-monster-learn-the-colors/

${ }^{9}$ http://www.technolio.com.br/app/
} 


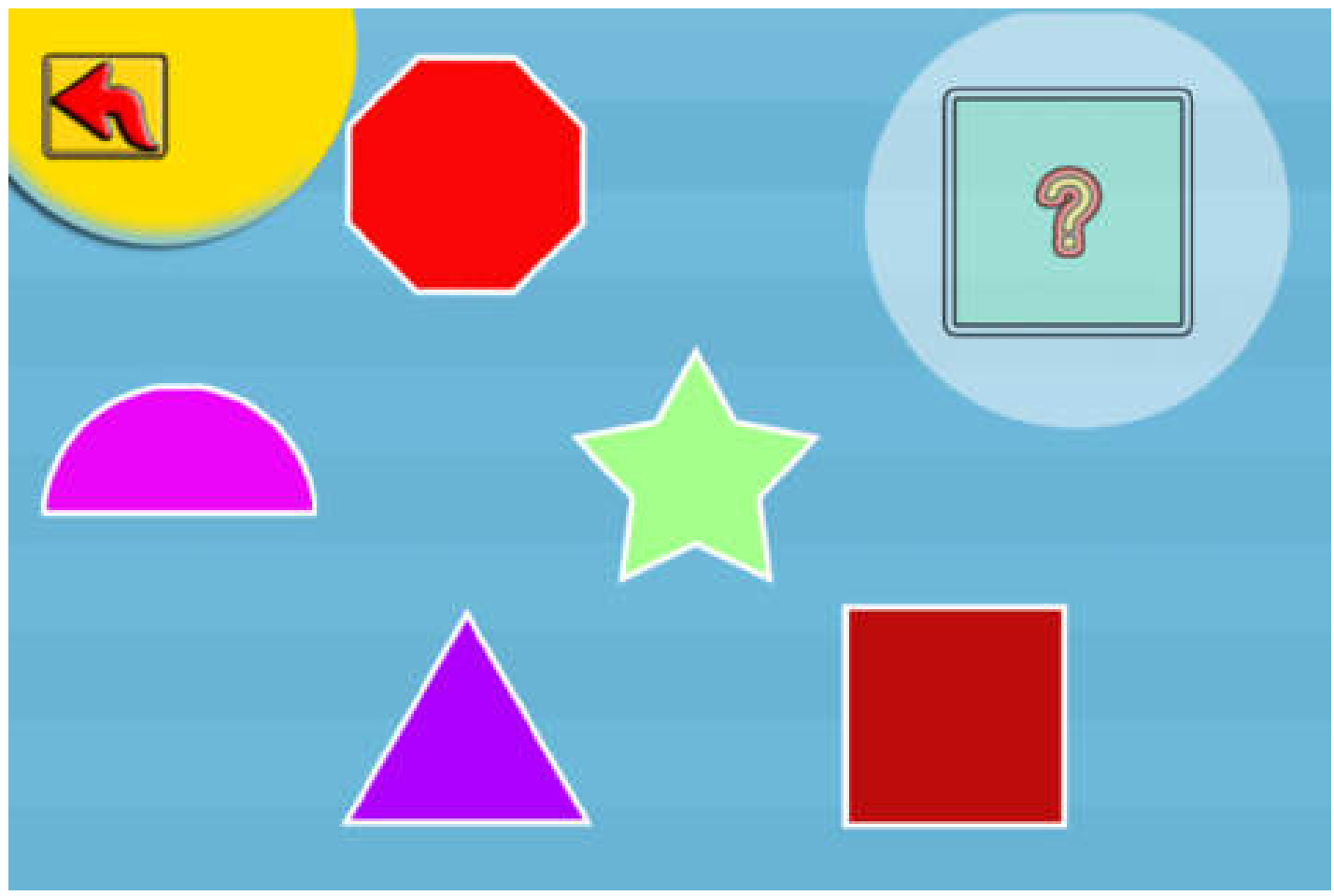

Figura 2: Aplicativo TP-Shape.

3. ABC Palavras ${ }^{10}$ : aplicativo de pareamento de letras. Inicia-se com as letras embaralhadas no topo da tela e o desenho da palavra a parear. Logo abaixo, se encontra a palavra relacionada a imagem com a ordem das letras corretas, porém as letras estão sem cor. A cada letra colocada no lugar incorreto o aplicativo emite um som de erro, e a cada letra colocada no lugar correto o aplicativo emite um som para indicar acerto. Ao terminar de colocar todas as letras no lugar correto o aplicativo emite o som da palavra finalizada. Uma imagem ilustrativa do aplicativo pode ser observada na Figura 3.

\footnotetext{
${ }^{10}$ http://www.technolio.com.br/app/, mesmo link utilizado para acessar o aplicativo TP-Shape.
} 


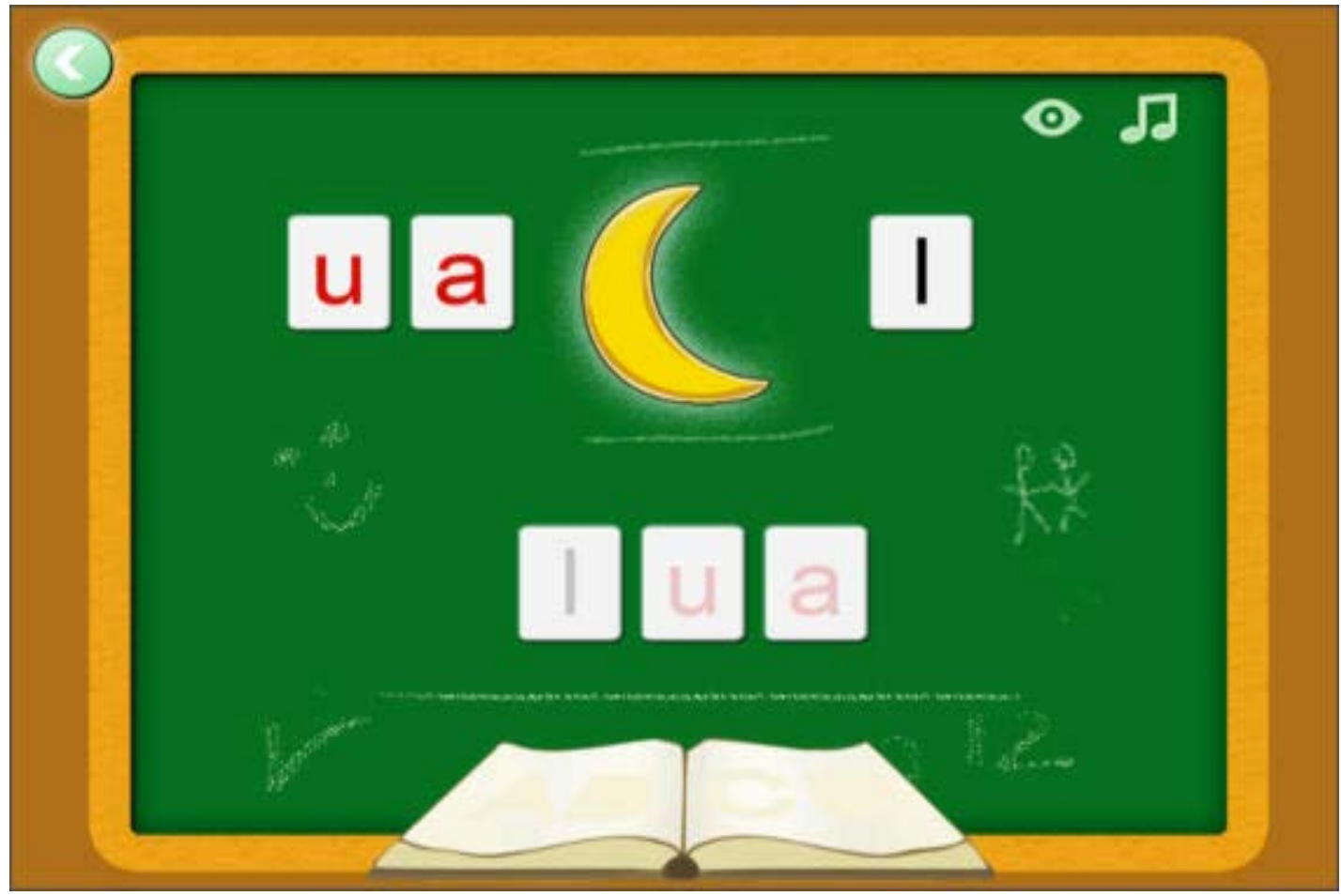

Figura 3: Aplicativo ABC Palavras.

O aplicativo também emite o som de cada letra ao ser clicada. Há uma música de fundo, a qual pode ser desabilitada e o idioma também é configurável. Para as observações desta pesquisa a música de fundo não foi desabilitada, com objetivo de observar como as crianças reagiriam a este recurso.

4. Doodlecast: aplicativo para estimular a criatividade e criação através da atividade de completar desenho ou fazer um desenho livre. Não possui sons durante a atividade. Uma imagem ilustrativa do aplicativo pode ser observada na Figura 4.

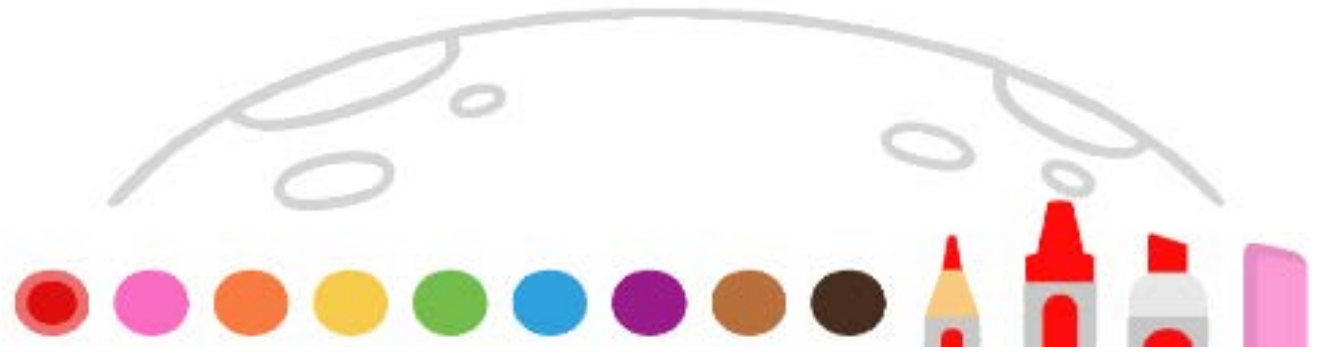

Figura 4: Aplicativo Doodlecast. 
5. Seasons ${ }^{11}$ : aplicativo de pareamento de formas e raciocínio lógico. Logo no início apresenta um menu com quatro atividades a serem feitas com o tema verão. As atividades são: montar um quebra cabeça, pareamento de formas geométricas, vestir um personagem, e uma atividade de contagem numérica. Após finalizar as quatro atividades outras quatro atividades são exibidas com o tema de outra estação do ano. Existe som para indicar erro e outro para indicar acerto. Também possui a funcionalidade para desabilitar a música de fundo. Entretanto, para fins de observação a música não foi desabilitada. Uma imagem ilustrativa do aplicativo pode ser observada na Figura 5.

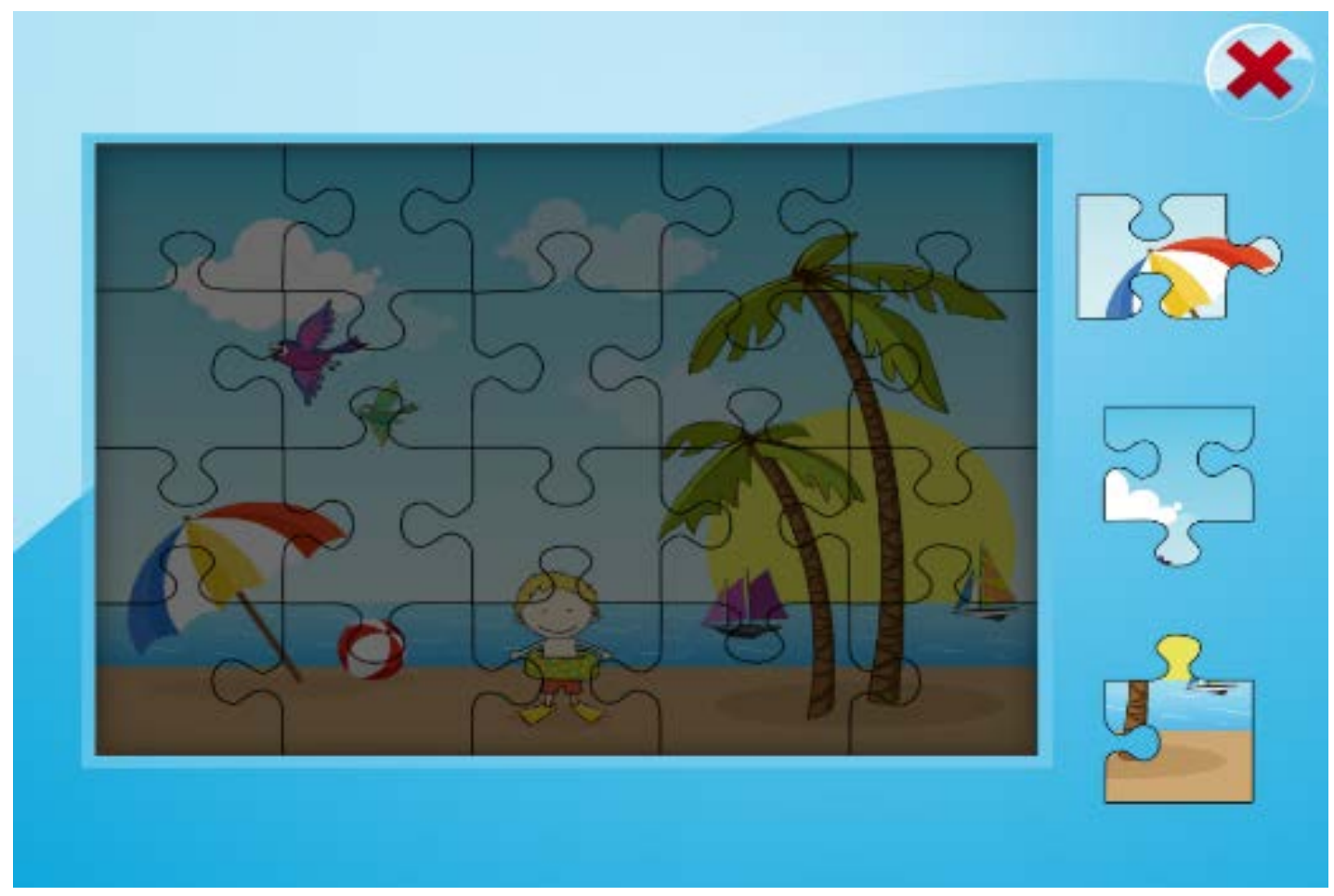

Figura 5: Aplicativo Seasons.

6. 123 Color $^{12}$ : aplicativo de pareamento de letras. O aplicativo apresenta o contorno de um desenho para colorir e nos espaços em branco há números ou letras. Logo abaixo do desenho há uma sequência numérica com cada número relacionado a uma cor, ou o alfabeto. O usuário deve procurar um número/letra do alfabeto que corresponde com um número/letra no desenho, clicar sobre ela, e depois clicar no número/letra sobre o desenho. No aplicativo também há som para indicar acerto e erro, e uma música de fundo. Uma imagem ilustrativa do aplicativo pode ser observada na Figura 6.

\footnotetext{
${ }^{11}$ http://www.cleverkiddoapps.com/seasons

12 https://kidcalc.wordpress.com/
} 


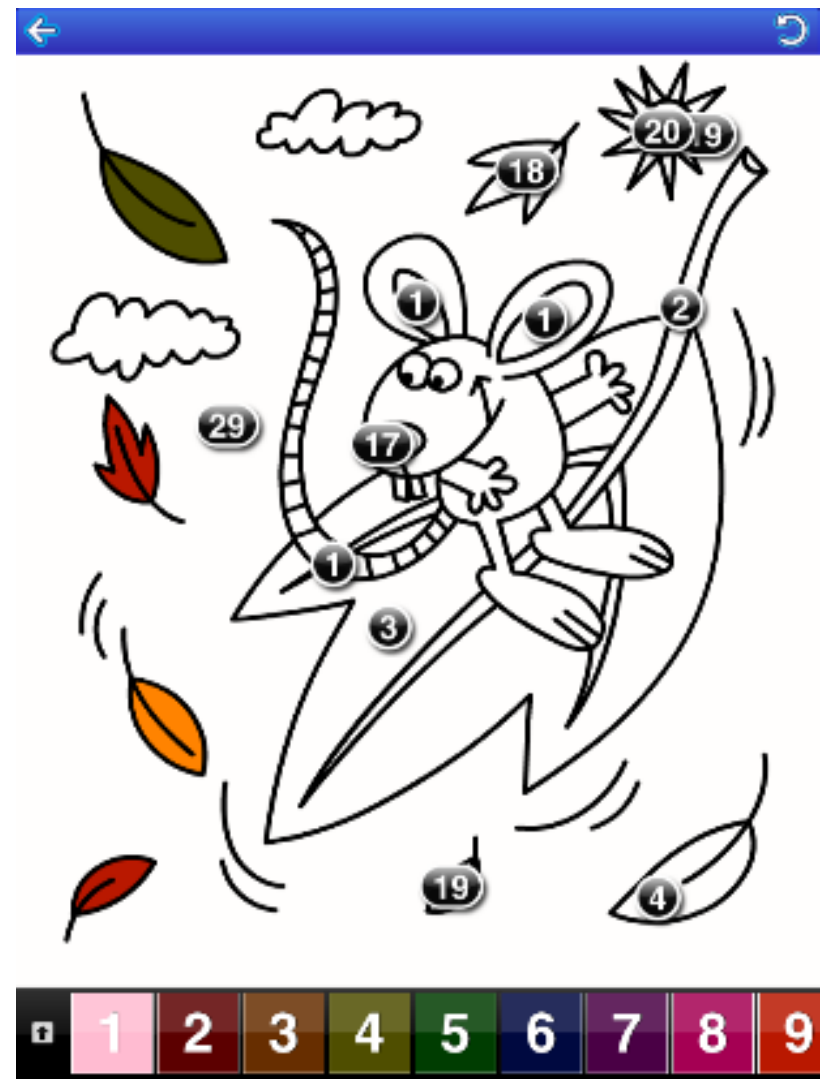

Figura 6: Aplicativo 123 Color.

As descrições a seguir referem-se ao dois aplicativos desenvolvidos especificamente para o público TEA.

7. Aiello ${ }^{13}$ : aplicativo de pareamento para ensinar vocabulário a crianças. O aplicativo é configurável em relação às categorias de palavras que podem ser pareadas. Outras funcionalidades do aplicativo podem ser customizadas, por exemplo, como realizar o pareamento. Para as observações foi utilizada a sombra da imagem e a figura-figura e palavra, utilizando as configurações padrões do aplicativo como observado na Figura 7. Outros itens que podem ser customizados: número de opções de palavras disponíveis para o usuário escolher, seleção visual, tipo de fonte e reforços automático. Ao entrar no aplicativo existe um avatar de um esquilo que interage com o usuário e também é apresentado um painel com a forma de algo a ser pareado pelo usuário, como exemplificado na Figura 7.

\footnotetext{
${ }^{13}$ http://www.jogoseducacionais.com/
} 


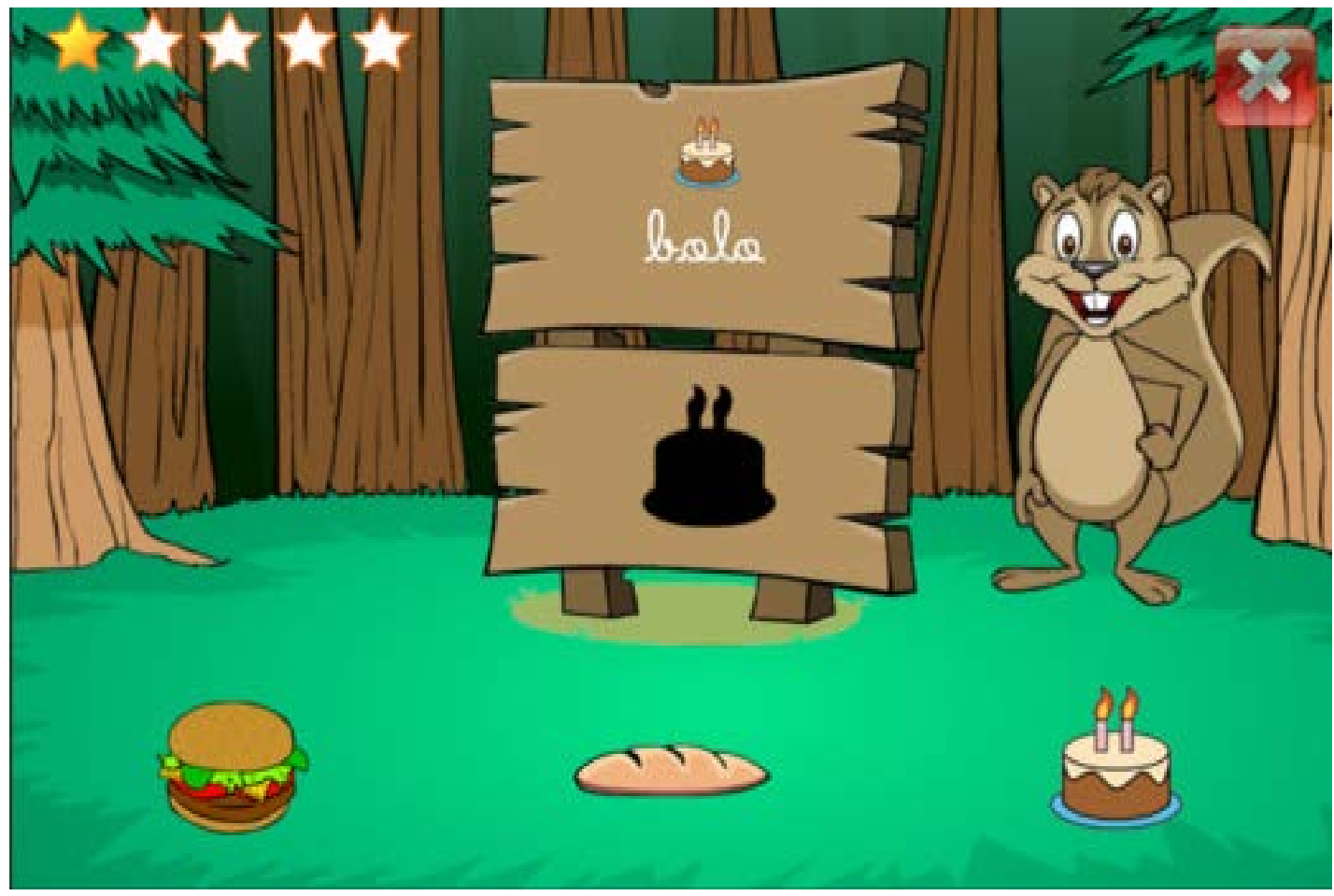

Figura 7: Aplicativo Aiello.

Ao escolher a forma correta o avatar emite o nome daquela forma e uma palavra de recompensa para incentivar o usuário. O avatar e os sons que este emite são configuráveis, assim como a indicação de erro expressa pelo avatar, a qual pode ser ocultada. Para as observações o avatar também foi utilizado com sua expressão de erro e sons, e também foi utilizada a opção de arrastar as imagens a serem pareadas, com a sombra da imagem.

8. Number Sequence ${ }^{14}$ : aplicativo desenvolvido para crianças com TEA que estimula o ensino de sequência numérica. $\mathrm{O}$ aplicativo inicia com uma introdução e com um pequeno tutorial ensinando como é o mecanismo do aplicativo. Ao iniciar o aplicativo uma sequência inicial é apresentada como: 1,2,3 e logo abaixo algumas opções de números. O usuário precisa escolher a opção da sequência mostrada. Há som para indicar acerto e recompensas visuais, mas nenhum som para indicar erro. O aplicativo também possui uma música de fundo. A sequência do aplicativo termina no número 7 . Uma imagem ilustrativa do aplicativo pode ser observada na Figura 8.

\footnotetext{
${ }^{14}$ https://itunes.apple.com/br/app/number-sequence-autism-series/id555257138?mt=8
} 


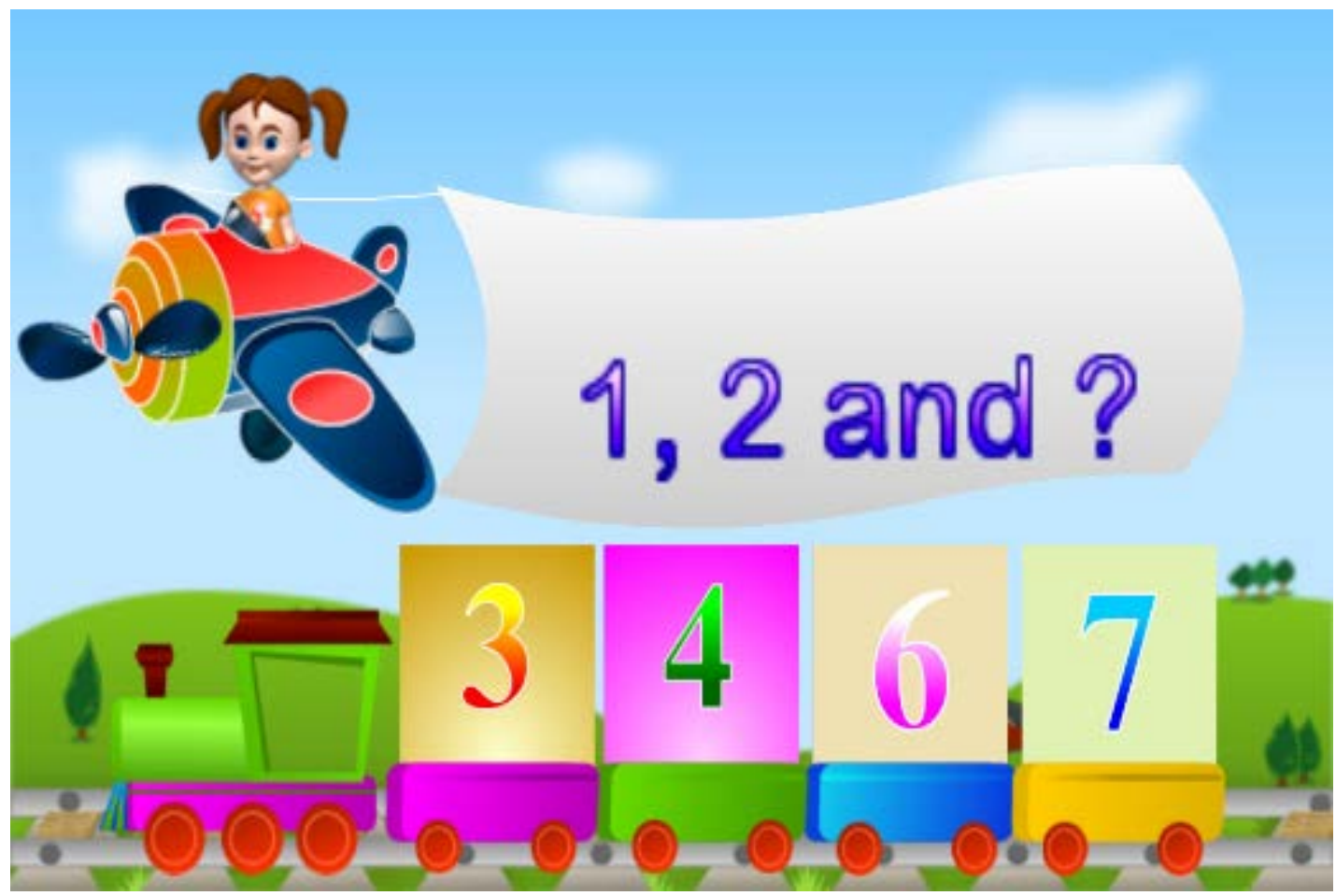

Figura 8: Aplicativo Nunber Sequence.

\subsection{Pesquisa de Campo: Questionários}

O segundo procedimento de coleta de dados para a pesquisa de campo foram os questionários. Compostos exclusivamente com perguntas abertas, os questionários foram distribuídos para os(as) profissionais de psicologia da clínica que acompanharam as crianças TEA durante as observações, e enviados por e-mail para os(as) responsáveis dos participantes. Para os dois públicos além dos questionários também foi enviado um termo de consentimento livre e esclarecido. Nestes questionários buscou-se conhecer a visão desses dois públicos sobre a interação dos indivíduos TEA com a tecnologia. Dos(as) profissionais procurou-se identificar como é a interação dos usuários TEA com os aplicativos como parte dos programas de tratamento. E dos(as) responsáveis buscou-se um maior conhecimento da interação das crianças TEA com a tecnologia no dia-dia, quando não estão usando para fins educacionais.

Dentre os(as) oito profissionais que participaram das sessões de observação, apenas cinco responderam os questionários. Para conhecer a visão desses profissionais sobre a interação dos indivíduos TEA com a tecnologia, os seguintes tópicos foram abordados no questionário:

- As considerações do(as) profissionais da clínica quanto a interação do público com TEA com a tecnologia; TEA;

- Situações vivenciadas pelos(as) profissionais durante o uso de softwares com as crianças

- Opinião dos(as) profissionais sobre a preferência de softwares do público TEA;

- As considerações dos(as) profissionais sobre softwares desenvolvidos especificamente para as pessoas TEA, e na opinião deles(as) qual a preferência das crianças com TEA: softwares específicos ou não específicos;

- Funcionalidades que os(as) profissionais gostariam de encontrar em um software desenvolvido para o público TEA; 
Para os(as) responsáveis das crianças TEA observadas buscou-se informações sobre a interação das crianças TEA com as tecnologias no dia-dia. Dentre os seis participantes TEA das observações apenas os responsáveis de duas crianças retornaram o e-mail enviado. Os tópicos abordados no questionário enviado aos responsáveis podem ser vistos a seguir:

- Quais tecnologias as crianças TEA usam quando estão em casa;

- Consideração dos(as) responsáveis quanto a interação dos seus filhos com a tecnologia;

- A frequência do uso de tecnologia no dia-dia da criança;

- Quais aplicativos que seus filhos mais se interessam, e na opinião dos(as) responsáveis qual a razão desta escolha;

- Quais situações os(as) responsáveis já presenciaram durante a interação de seus filhos com a tecnologia;

Tabela 4: Relação criança x responsáveis x profissionais que participaram da pesquisa.

\begin{tabular}{|c|c|c|}
\hline Crianças & Responsável & Profissional \\
\hline Criança A & Responsável 1 & Profissional 2 \\
\hline Criança B & - & Profissional 3,2 \\
\hline Criança C & - & Profissional 1 \\
\hline Criança D & - & Profissional 2 \\
\hline Criança E & Responsável 2 & Profissional 4,6 \\
\hline Criança F & - & Profissional 4 \\
\hline
\end{tabular}

\section{Discussão}

Nesta seção será realizada a análise dos resultados coletados na pesquisa de campo. Na primeira seção serão analisadas as observações das crianças com TEA interagindo com os aplicativos selecionados, e na segunda seção serão relatados e analisados os resultados obtidos pelos questionários enviados aos profissionais da clínica e aos responsáveis das crianças com TEA.

\subsection{Análise Observações}

Durante as observações pode-se notar que a maioria dos participantes TEA já havia tido contato prévio com algum tipo de dispositivo com tela sensível ao toque, como os smartphones e tablets, dada a desenvoltura dos mesmos durante as interações. Apenas a criança $F$ não sabia como interagir com o dispositivo utilizado nas observações, um tablet. Profissionais que a acompanharam necessitaram ajudá-la. Também pode-se observar nas crianças que já possuíam contato com tecnologias o quanto os aplicativos e o dispositivo tablet são atrativos para elas, ressaltando as considerações de Barry e Pitt (2006).

A seguir são relatados os resultados obtidos com as observações de cada aplicativo. A análise das interações está na ordem na qual os aplicativos foram utilizados (conforme Tabela 3). É importante ressaltar que todos os aplicativos foram usados com as mesmas configurações para todas as crianças. Isto deve-se ao fato de que os intervalos entre as observações eram pequenos e não havia tempo para customizá-los no recinto da observação, pois ao observar o tablet as crianças já apresentavam ansiedade por interagir com o dispositivo.

\section{TP-Shape (Dia 1)}

Durante a observação do jogo TP-Shape notou-se que todos os participantes presentes no dia 1 não encontraram dificuldades em aprender o mecanismo do aplicativo. Entretanto, três dos participantes não compreenderam o mecanismo de recompensa, no qual deveriam escolher um dos “adesivos” de sua preferência. Foi necessária a ajuda dos(as) profissionais acompanhantes. A 
imagem do recurso de recompensa apresentado pelo aplicativo pode ser observada na Figura 9. No aplicativo TP-Shape, quando o usuário realiza um movimento incorreto um som de erro é emitido, o qual soou agradável aos ouvidos das crianças B e F, níveis 2 de TEA. Apesar de não compreenderem de imediato o recurso de recompensa todas as crianças mantiveram o interesse pelo aplicativo ao menos uma vez após a recompensa de escolher um "adesivo" (figuras na parte inferior da Figura 9). Tal recompensa também foi usada pelos(as) profissionais que acompanhavam a observação como um recurso motivacional.

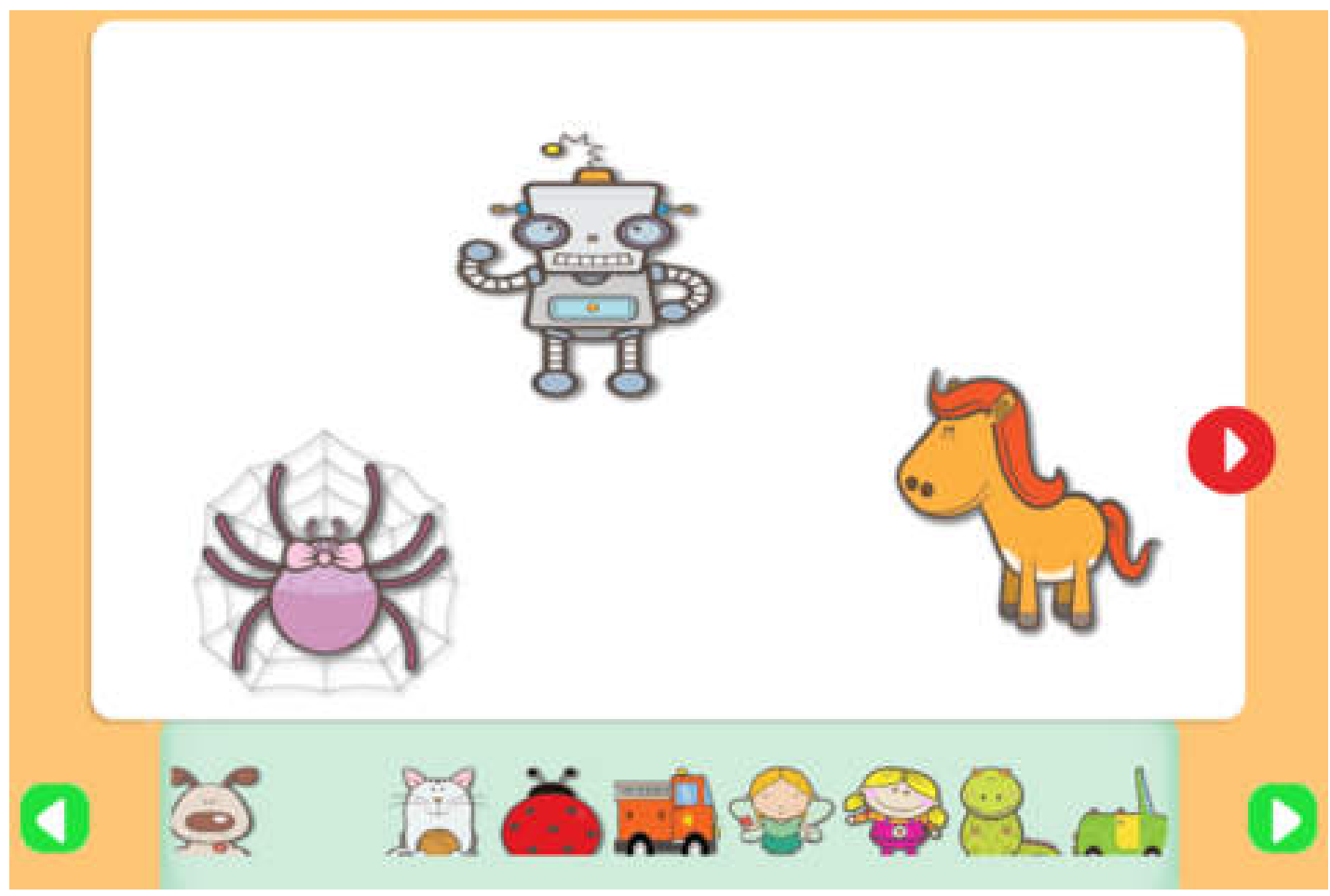

Figura 9: Como recurso de recompensa os usuários podem selecionar “adesivos” de sua preferência.

O aplicativo também possui repetição reforçadora, ou seja, as sequências do aplicativo se repetem sem mudar o nível de dificuldade. Segundo os(as) profissionais da clínica, a repetição é muito importante para as crianças TEA no processo de aprendizagem, pois eles se distraem facilmente. Porém, o que se observou é que para as crianças B e E o aplicativo se tornou monótono depois de algumas repetições. Sem um desafio, as crianças perderam o interesse pelo aplicativo rapidamente e só continuaram devido ao incentivo dos(as) profissionais de psicologia que os acompanhavam ou/e pelo recurso de recompensa. De acordo com o profissional 6 que acompanhava a criança E, os softwares poderiam apresentar níveis de dificuldade gradativos.

\section{ABC Palavras (Dia 1)}

As crianças observadas durante a interação com o aplicativo ABC-Palavras também não apresentaram dificuldades com o mecanismo do aplicativo. Alguns já eram familiarizados com o aplicativo pois, já o utilizava na clínica. O aplicativo ABC-Palavras emite os sons das letras ao clicá-las para pareá-las. Observou-se que as crianças B, E e F repetiam os sons emitidos pelo aplicativo, confirmando uma das possíveis características dos indivíduos TEA que é a ecolalia. A profissional que acompanhava a criança B notou que alguns dos sons das letras ao serem selecionadas estavam erradas. No caso da palavra xícara, ao clicar sobre a letra X o som emitido era /xi/ e não o som da letra /xis/. Como no aplicativo anterior, as crianças B e E também apresentaram uma certa irritação com a monotonia do aplicativo que não aumentava o nível de dificuldade. 


\section{Seasons (Dia 2)}

As crianças compreenderam bem o mecanismo do aplicativo Seasons. Durante a observação pode-se notar uma certa dificuldade de algumas crianças TEA na percepção holística. As crianças $\mathrm{A}$ e $\mathrm{C}$, ao selecionarem as peças do quebra-cabeça se atentavam mais à marca d'água do quebra-cabeça do que para as formas das peças, como visto na Figura 5. Por se atentarem mais ao desenho da marca d'água as crianças muitas vezes erravam e acabavam se frustrando e desistindo do aplicativo. Algumas crianças, como a A e, C encontraram uma leve dificuldade em arrastar elementos de um lado a outro do tablet, no quebra-cabeça presente no aplicativo, insistindo nos movimentos até conseguir realizá-los sem ajuda, ou quando não conseguiam realizá-los demonstravam frustração e os(as) profissionais os auxiliavam. Segundo os(as) profissionais que acompanhavam os indivíduos TEA, estes podem apresentar prejuízos na motricidade fina, como o caso da criança $\mathrm{C}$, assim arrastar os elementos no tablet pode auxiliálos a desenvolver os movimentos que exigem maior precisão.

\section{Doodlecast (Dia 2)}

Durante a observação do aplicativo Doodlecast todas as crianças que estavam presentes no dia dois (A - 8 anos e nível 2 de TEA; B - 6 anos e nível 2 de TEA; C - 6 anos e nível 1 de TEA) apresentaram grande dificuldade em criar algo espontaneamente. Durante a observação deste aplicativo, os(as) profissionais pediam as crianças que desenhassem algo como uma casa, flores e árvores, mas elas apenas arrastavam o dedo sobre a tela criando rabiscos.

Durante as observações os(as) profissionais comentaram que os indivíduos TEA têm muita dificuldade em criar algo espontâneo e que preferem algo concreto e estruturado. Entretanto, o aplicativo é utilizado na clínica como um meio para auxiliar o desenvolvimento da motricidade fina pois o mesmo possui telas como o da Figura 4 em que as crianças podem contornar os desenhos.

\section{Aiello (Dia 3)}

O aplicativo Aiello era novo para todos os participantes na clínica, foi uma sugestão da observadora aos profissionais. Durante a observação as crianças não encontraram dificuldade em aprender o mecanismo do aplicativo. Aiello possui um avatar para interagir com os usuários e ao observar a interação das crianças com o aplicativo notou-se que algumas crianças como os participantes A e F gostaram do avatar do aplicativo, e também das recompensas sonoras e visuais apresentadas pelo aplicativo. Porém os outros participantes do dia três das observações, B, C, D e E, mostraram um certo desconforto com os elementos visuais que reportam o feedback de acerto, como o texto colorido piscando e os "fogos de artifício" na tela. A tela do aplicativo com a imagem do feedback de acerto pode ser observada na Figura 10. Também se notou a repetição dos sons de acerto por parte da criança F. 


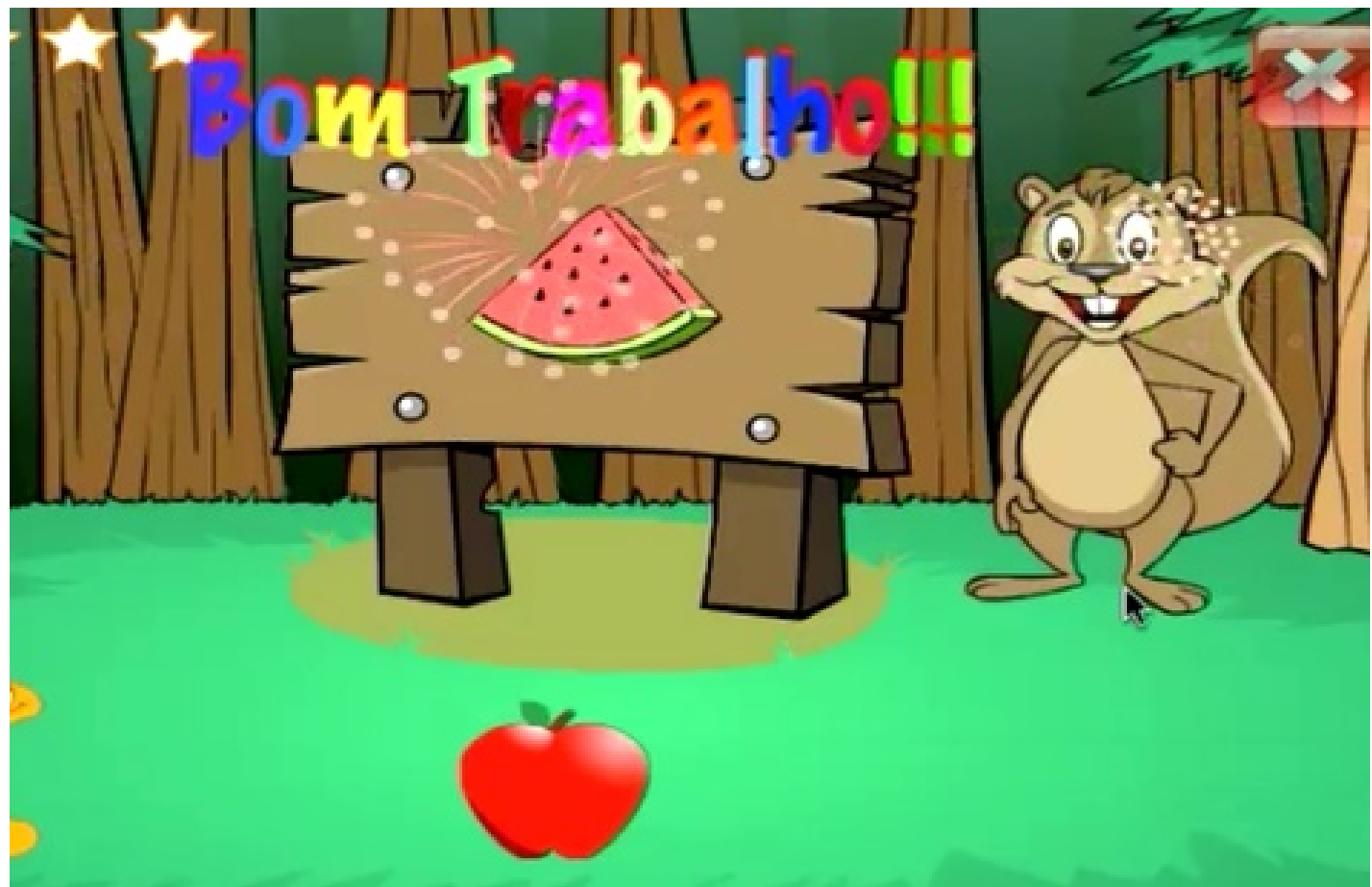

Figura 10: Aiello-Recurso de Recompensa.

Este aplicativo foi desenvolvido por Cunha (2011), o qual destaca o uso de poucas ações para manter o foco na tarefa a ser realizada em seu trabalho. Para a realização das tarefas propostas por esse aplicativo são realizadas poucas ações e as crianças com TEA observadas nesta pesquisa não encontraram dificuldades em lembrar das ações deste aplicativo após alguma distração com objetos disponíveis na sala, ou com barulhos externos a sala de observação. O aplicativo Aiello também apresentou uma pequena lentidão ao reportar os feedbacks de acerto, devido ao sistema operacional antigo do tablet. Isso causou um certo estranhamento nos participantes TEA, provocando reações como a da criança $\mathrm{B}$, que ao perceber a demora no retorno do acerto exclamou: "Não faz barulho!" e pedindo em seguida para trocar de aplicativo.

\section{Color (Dia 3)}

Com o aplicativo 123 Color os participantes A, C, D e F apresentaram dificuldade em compreender o mecanismo do jogo, como as idades e níveis de TEA são distintos não foi possível mapear a razão da dificuldade encontrada. Os(as) profissionais que os acompanharam necessitaram interferir e lhes mostrar mais de uma vez o funcionamento do aplicativo. Outra dificuldade notada na observação das crianças com o aplicativo 123 Color, foi a dificuldade das crianças A C, D e F em recordar a sequência de passos para realizar um movimento correto no aplicativo, não sendo possível identificar a razão da dificuldade encontrada devido a variedade de idade e níveis de TEA das crianças. A cada distração com objetos disponíveis na sala, ou barulhos externos as crianças se desconcentravam e os profissionais precisavam recordá-las da sequência. Também durante a observação do 123 Color observou-se que um elemento na tela tirava o foco de algumas crianças da tarefa a ser realizada. Na Figura 11 pode-se observar um pequeno elemento na interface do aplicativo 123 Color, indicado por uma flecha no canto inferior esquerdo na imagem, que ao ser clicado gira. As crianças A e F, níveis 2 de TEA e D, nível 3 de TEA, ao notar esse elemento durante as observações perdiam o foco da atividade e clicavam sobre ele repetidamente para observar o elemento girar. Os(as) profissionais que os acompanhavam interferiam e chamavam a atenção para continuar o aplicativo. Uma das características que pessoas com TEA podem apresentar é o fascínio com o movimento de peças, como descrito pelo Manual Diagnóstico e Estatístico de Transtornos Mentais (American Psychiatric Association \& Others, 2014). 


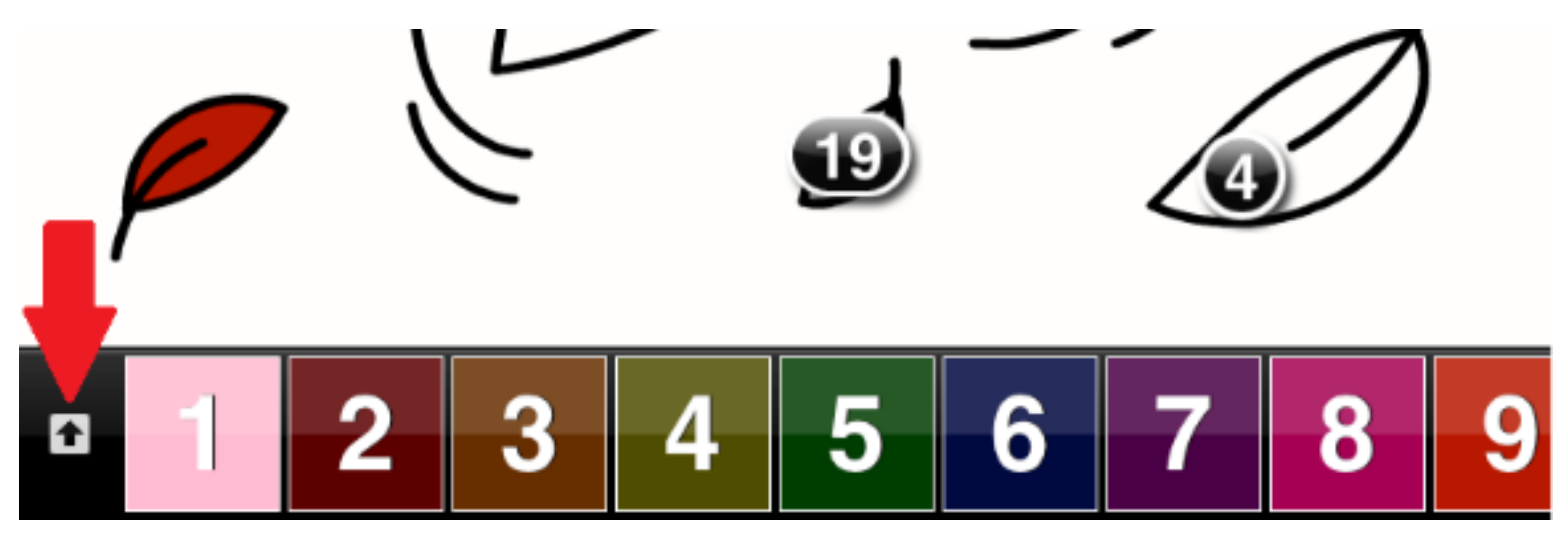

Figura 11: Elementos da Tela.

\section{Number Sequence (Dia 4)}

Durante a observação do Number Sequence as crianças encontraram dificuldade em entender o mecanismo do aplicativo. A maioria das crianças TEA observadas ao receberem o tablet logo arrastavam seu dedo sobre a tela procurando alguma resposta visual ou sonora do aplicativo. No aplicativo Number Sequence antes de iniciar o aplicativo há um breve vídeo com um tutorial. Ao receber o tablet, com este tutorial sendo exibido, as crianças percorriam a tela com o dedo buscando uma resposta visual ou sonora do aplicativo que não acontecia, demonstrando impaciência para assistir ao vídeo. As crianças A B, C e E apresentaram uma certa irritação pelo aplicativo não iniciar de imediato e solicitavam para trocar ou apenas fechavam o aplicativo. A criança A e B buscavam pareamentos e quando não encontravam clicavam em qualquer número da tela, apenas com a ajuda dos(as) profissionais conseguiram interagir com o aplicativo. A recompensa sonora também influenciou a motivação, quando não a encontravam solicitavam para trocar o aplicativo.

\section{Color Monster (Dia 4)}

O aplicativo Color Monster foi o predileto das crianças do último dia de observação. Acredita-se que isto se deve ao fato de serem familiarizados com o aplicativo. Consequentemente, as crianças não encontraram dificuldades com o funcionamento do aplicativo. Como no aplicativo TP-Shape, os sons e as falas emitidas pelo avatar que indicam erro também soaram mais divertidos para alguns dos participantes, como as crianças A B e D. Este comportamento também foi mencionado pelos(as) profissionais, e segundo eles(as), analisar os tipos de sons de um aplicativo é uma das suas preocupações ao selecioná-los para fins educacionais a seus(suas) pacientes TEA. No aplicativo há um avatar que interage com o usuário emitindo sons para quando o usuário erra ou acerta, a imagem do avatar do aplicativo Color Monster pode ser observada na Figura 1.

O incentivo por meio de sons e imagens após finalizar uma atividade no aplicativo ou também avatares interagindo com as crianças foi percebido como algo reforçador para os participantes TEA, incentivando-os a continuar as atividades propostas. Também se notou a repetição por parte das crianças dos sons emitidos pelo aplicativo.

\subsection{Análise Questionários}

Nesta seção será analisado os resultados obtidos nos questionários enviados aos profissionais que acompanharam as crianças TEA durante as observações e também aos responsáveis das crianças TEA.

Nos questionários enviados aos profissionais foi perguntado sobre situações vivenciadas por eles(as) durante o uso de softwares com crianças TEA, deste modo as profissionais 3 e 4 relatam a preferência de seus(suas) pacientes TEA a sons que indicam erro sobre os sons que indicam acerto, sendo uma preocupação delas ao selecionar um software para realizar uma atividade. 
Situação esta também notada durante as observações realizadas na pesquisa de campo, com o aplicativo TP-Shape e Color Monster.

Quanto a preferência de softwares por indivíduos TEA o profissional 6 e a profissional 2 contam que os indivíduos TEA preferem softwares que possuam música, estímulos visuais e sonoros. A profissional 4 e o profissional 1 dizem que os indivíduos TEA preferem softwares que seguem algum padrão gráfico, com cores e forma geométricas bem definidas, e que o excesso de informação não torna o software viável para se trabalhar com o indivíduo TEA. Por último a profissional 3 adiciona que softwares com personagens como avatares, também são atrativos, assim como muitas cores na tela e sons "engraçados".

Durante as observações pode-se notar que os comentários feitos pelos(as) profissionais nos questionários são realmente válidos, pois o incentivo por meio de sons e imagens após finalizar uma atividade no jogo ou também avatares interagindo com as crianças foi percebido como algo reforçador para os participantes TEA. Notou se que este recurso os incentivou a continuar as atividades propostas, como observado nas interações dos participantes com os aplicativos Color Monster, Aiello e TP-Shape.

Apenas a profissional 4 reportou já ter trabalhado antes com softwares específicos para o público TEA. Na sua opinião, a grande maioria dos softwares desenvolvidos especificamente para o grupo TEA estão em inglês e/ou são pagos. Como apenas a profissional 4 já havia trabalhado com softwares específicos e não específicos para o público TEA, apenas esta profissional argumentou sobre o tópico quatro dos questionários, relatando que softwares desenvolvidos para o público em geral são mais atraentes por serem mais coloridos e cheios de sons.

Todos(as) os(as) profissionais reportaram que gostariam de encontrar funcionalidades nos softwares desenvolvidos para o público TEA. O profissional 1 e a profissional 2 comentam que gostariam de encontrar softwares que exigissem respostas verbais dos indivíduos, pois uma das características que crianças diagnosticadas com esse transtorno podem apresentar são dificuldades na comunicação. Softwares que exijam respostas verbais das crianças podem auxiliar no desenvolvimento da fala e compreensão, além da aquisição de vocabulário. Já a profissional 3, gostaria de ter a possibilidade para configurar eventuais sons emitidos pelos softwares, além da adaptação do idioma e meios para que a criança não saia por conta própria da atividade proposta no software.

Durante as observações as crianças TEA que participaram dessa pesquisa, no geral, apresentaram uma certa resistência em solicitar ou aceitar ajuda quando encontravam dificuldades durante as atividades nos aplicativos. E quando encontravam resistência em realizar a atividade proposta no aplicativo, logo procuravam os botões de saída do software ou o do próprio tablet. Deste modo validando a preocupação da profissional 3 sobre os bloqueios para que os usuários não saiam por conta própria da atividade.

A profissional 4 e o profissional 6 comentam sobre os reforços positivos e negativos sendo alocados estrategicamente no software para o estabelecimento de comportamentos adequados. Isto deve ser feito para evitar comportamentos observados como o do jogo Color Monster e TPShape, no qual algumas crianças repetiam as ações incorretas para ouvir o som que lhes era agradável.

De acordo com o profissional 6, este gostaria de encontrar em softwares desenvolvidos para o público TEA graus de dificuldades sendo apresentados gradativamente. Dois dos aplicativos utilizados, como o TP-Shape e Number Sequence possuem repetição reforçadora, ou seja, as sequências do jogo se repetem sem mudar o nível de dificuldade. O ABC-Palavras não apresenta repetições de uma mesma sequência, mas o nível de dificuldade também não aumenta ao decorrer do jogo. Segundo os(as) profissionais da clínica, a repetição é muito importante para as crianças TEA no processo de aprendizagem, pois eles se distraem facilmente. Para a maioria das crianças 
os jogos se tornaram monótonos depois das primeiras repetições, sem um desafio as crianças perderam o interesse pelo jogo rapidamente e muitos só continuaram devido ao incentivo dos(as) profissionais de psicologia que os acompanhavam.

As responsáveis dos participantes TEA, responsável 1 e 2, em seus questionários relataram que as crianças utilizam dispositivos, como os smartphones e tablets em casa, sendo a maior parte do tempo dedicada para o lazer, com o uso livre, e ainda consideram a interação com a tecnologia saudável. Em razão das crianças com TEA terem acesso a esses dispositivos em casa, os(as) profissionais de psicologia comentaram durante as sessões que é necessário diferenciar o uso do tablet na clínica como uma atividade educacional. Quando as crianças percebem esse dispositivo como lazer, é difícil realizar as atividades propostas, podendo desencadear nas crianças TEA comportamentos não esperados como os observados durante as sessões na clínica. Por exemplo, as crianças A e D, segundo os(as) profissionais, utilizam o tablet em casa, e quando foram sugeridos os aplicativos do dia da observação as crianças se recusaram a realizar a atividade proposta e procuraram o aplicativo que lhes interessava. Os(as) profissionais que os acompanhavam tentaram algumas vezes voltar para a atividade, porém as crianças demonstraram um certo nervosismo.

A responsável da criança A reportou que ele gosta muito de assistir vídeos, principalmente de outras crianças, além de gravar e tirar fotos. A responsável ainda completou contando que a criança A ainda não sabe ler ou escrever, mas consegue encontrar o que quer nos dispositivos. Já a responsável da criança $E$ reportou que considera a interação do seu filho com a tecnologia natural, e informou que a criança A utiliza as tecnologias reportadas todos os dias de duas a três horas, tendo como objetivo lazer e as vezes educacional. Já a responsável 2 relata que seu filho utiliza as tecnologias reportadas três vezes ao dia de 30 a 40 minutos, para o lazer.

A responsável 1 também relatou que seu filho usa aplicativos, e que ela acredita que o maior interesse dele em usar esses aplicativos é para passar o tempo. A responsável 2 relatou que seu filho não usa aplicativos.

As duas responsáveis relataram situações onde seus filhos ficaram nervosos e irritados durante o uso de alguma tecnologia. A responsável 1 conta que seu filho fica irritado quando algum jogo na celular trava, relatando que é sempre um transtorno quando acontece. A responsável 2 apenas relata a reação do seu filho não explicando o motivo que desencadeou tal reação.

\section{Resultados}

Com a pesquisa bibliográfica pode-se reunir uma lista com 17 recomendações, para o desenvolvimento de artefatos tecnológicos para crianças com TEA. Dentre todas as recomendações encontradas esta pesquisa confirma, ou seja, foram possíveis de observar durante a pesquisa de campo, 12 recomendações ${ }^{15}$.

Na Tabela 5 poderá ser observada uma listagem das recomendações confirmadas por esta pesquisa, e uma breve descrição sobre elas em seguida.

\footnotetext{
15 As recomendações compiladas por Britto e Pizzolato (2018) não foram possíveis serem analisadas pois as observações com as crianças TEA ocorreram anteriormente a esta referência, porém essas recomendações complementam outras recomendações analisadas nesta pesquisa.
} 
Tabela 5: Recomendações confirmadas pela pesquisa.

\begin{tabular}{|c|c|}
\hline Recomendação & Feita por/em \\
\hline Fazer com que o indivíduo se sinta no controle. & Van Rijn e Stappers (2008) \\
\hline Criar uma situação estruturada. & $\begin{array}{c}\text { Van Rijn e Stappers (2008), Millen (2007) apud Millen } \\
\text { et al. (2010), Dautenhahn (2000) }\end{array}$ \\
\hline Deixar o indivíduo TEA criar uma situação estruturada & Van Rijn e Stappers (2008) \\
\hline Recompensá-los com experiências sensoriais & Van Rijn e Stappers (2008), Dautenhahn (2000) \\
\hline Facilitar o olhar dos indivíduos TEA para o detalhe & Van Rijn e Stappers (2008), Dautenhahn (2000) \\
\hline Deixá-los usar todo o corpo & Van Rijn e Stappers (2008), Dautenhahn (2000) \\
\hline Ambientes controlados e seguros & Dautenhahn (2000), Barry et al. (2008) \\
\hline Ambientes customizados & Edlin-White (2009), Millen (2007) apud Millen et al. \\
\hline \begin{tabular}{c} 
(2010) \\
\hline Um software não pode confiar inteiramente em texto e \\
linguagem para instrução e comandos
\end{tabular} & Millen 2007 apud Millen et al. (2010) \\
\hline Recurso de repetição usado com variação & Edlin-White (2009) apud Millen et al. (2010) \\
\hline Evitar sobrecarga cognitiva & Barry et al. (2008) \\
\hline Interface clara & Barry et al. (2008) \\
\hline
\end{tabular}

Fazer com que o indivíduo se sinta no controle: A maneira com que crianças TEA processam informações as fazem sentir como se elas possuíssem pouco ou nenhum controle sobre situações, de acordo com Van Rijn e Stappers (2008). Por esta razão, as crianças gostam de interações que as fazem pensar que estão no controle da situação. Os autores citam o feedback imediato como um meio para prover essa segurança, assim durante as observações notou-se que as crianças repetiam algumas ações ao interagir com os aplicativos pois já conheciam determinados sons que lhes agradavam, assim realizando o mesmo movimento repetidamente, como notada na interação do aplicativo Color Monster.

Criar uma situação estruturada: Crianças TEA podem apresentar grande dificuldade em desenvolver a imaginação por isso uma situação estruturada pode lhe ser mais adequada, criando ambientes onde o usuário saiba o que é esperado dele, como os jogos de pareamento de formas geométricas, palavras e quebra-cabeças. Durante as observações pode-se confirmar a recomendação de Millen, (2007) apud Millen et al. (2010) e Van Rijn e Stappers (2008), pois foi notada a preferência das crianças pelos aplicativos de pareamento, como o TP-Shape, ABCPalavras, Aiello, sobre o aplicativo Doodlecast, o qual não apresenta pareamento.

Deixar o indivíduo TEA criar uma situação estruturada: Não só as crianças com TEA gostam de uma situação estruturada como gostam de criar situações estruturadas. Segundo Van Rijn e Stappers (2008), as crianças com TEA criam estruturas quando tornam explícitas as diferenças. Situação também observada em alguns participantes desta pesquisa, que apresentaram interesse e facilidade pelos aplicativos de pareamento onde podem classificar coisas além de trabalhar com similaridades.

Recompensá-los com experiências sensoriais: Crianças com TEA frequentemente gostam de sensações específicas, como relata Van Rijn e Stappers (2008) em seu trabalho. Embora essas crianças possam ser muito sensíveis aos estímulos, eles realmente gostam de recompensas sensorias, como música, sons, etc. Durante as observações alguns participantes também mostraram preferência por sons que os aplicativos utilizados emitiam, como por exemplo os sons, os avatares interagindo com elas, além dos recursos de recompensa, os quais mantiveram a atenção das crianças observadas nesta pesquisa. Os(as) profissionais em seus questionários também reforçam esta recomendação, pois relatam a preferência de crianças por softwares com músicas, e estímulos sonoros e visuais, além do uso dos avatares, porém destacam o uso destes recursos com moderação. 
Facilitar o olhar dos indivíduos TEA para o detalhe: Crianças TEA possuem dificuldade com a percepção holística, por isso o foco no detalhe, como cor ou forma, etc., torna mais simples a compreensão, como Van Rijn e Stappers (2008) e Dautenhahn (2000) relatam em suas recomendações. Pode-se confirmar através das observações que as crianças TEA possuem mais facilidade quando focam nos detalhes. Chamou a atenção também durante as observações do jogo Seasons, que as crianças se atentavam mais a marca d'agua do quebra cabeça e aos desenhos e cores do que para o formato das peças. Assim, focar em apenas um detalhe torna mais simples a compreensão do que é esperado dos usuários TEA.

Deixá-los usar todo o corpo: Van Rijn e Stappers (2008) e Dautenhahn (2000) comentam em suas recomendações que possibilitar as crianças com TEA a usar todo o seu corpo quando estão interagindo com algum artefato, possibilita a interação com outros indivíduos e a experimentar sensações multissensoriais. Durante uma das interações com o tablet, um dos participantes TEA se levantava e andava pela sala. A profissional que o acompanhava relatou que este é um comportamento típico deste participante, quando está empolgado, confirmando a recomendação dos autores(as).

Ambientes controlados e seguros: Fornecer meios para que a criança com TEA não possam sair dos jogos sem o consentimento do(a) profissional ou responsável que está aplicando alguma atividade, é o que sugere a recomendação de Dautenhahn (2000) e Barry et al. (2008). Situação também observada nas seções com as crianças TEA desta pesquisa, pois muitas vezes as crianças saiam da atividade proposta com os aplicativos sem o consentimento do(a) profissional que os estavam acompanhando.

Ambientes customizados: De acordo com Edlin-White (2009) apud Millen et al. (2010) soluções deveriam ser, na medida do possível, fáceis e rápidas de serem customizadas. Durante a pesquisa de campo se notou que o som de erro muitas vezes soou para a criança TEA mais chamativo do que o som para indicar acerto. Possibilitar a customização, ou ocultar esses sons, permite aos profissionais e responsáveis que eles possam adaptar esses recursos a cada criança, recomendação também observada por Millen (2007) apud Millen et al. (2010), que sugere a customização do volume dos sons. Além da possibilidade de customizar outros recursos dos softwares, como volume de músicas e sons, níveis de dificuldade, recursos de incentivos, e etc.

Um software não pode confiar inteiramente em texto e linguagem para instrução $e$ comandos: Crianças com TEA são visuais, e possuem dificuldade em abstração, assim as imagens as auxiliam no entendimento de alguma instrução ou comando. As observações confirmam a recomendação de Millen (2007) apud Millen et al. (2010) e também a de Van Rijn e Stappers (2008), os quais apontam a importância de informar as crianças TEA visualmente sobre o que é esperado delas.

Recurso de repetição usado com variação: A repetição é muito importante para crianças com TEA para reforçar aquilo que foi aprendido, mas deveria ser utilizada com variação para manter o interesse da criança no jogo, como mencionado pelos(as) profissionais nos questionários, confirmando a recomendação de Edlin-White (2009) apud Millen et al. (2010).

Evitar sobrecarga cognitiva: De acordo com Barry et al. (2008) muitos estímulos visuais podem deixar crianças com TEA desconfortáveis. Por exemplo, durante as observações também pode-se notar que algumas crianças apresentavam um certo desconforto quando expostas a estímulos visuais do aplicativo Aiello utilizados durante a pesquisa de campo.

Interface Clara: Nesta recomendação é indicado que as interfaces sejam simples e claras, com poucos elementos na tela, evitando peças com movimentos, de acordo com Barry et al. (2008) crianças TEA podem se concentrar em detalhes aparentemente irrelevantes. Durante as observações foi possível notar a distração com elementos da interface do aplicativo 123 Color que para outros usuários poderiam ser irrelevantes. Deste modo, verifica-se também que o uso de 
animações deve ser evitado em jogos educativos para crianças com TEA, se a animação não tiver um objetivo relacionada com o processo de aprendizagem da criança.

$\mathrm{Na}$ Tabela 6 podem ser observadas as recomendações encontradas na pesquisa bibliográfica que não foram possíveis de observar durante a pesquisa de campo.

Tabela 6: Recomendações não observadas na pesquisa.

\begin{tabular}{|c|c|}
\hline Recomendação & Feita por/em \\
\hline Usar os interesses especiais de cada indivíduo & Van Rijn e Stappers (2008) \\
\hline Generalização & Dautenhahn (2000) \\
\hline Elementos competitivos deveriam ser omitidos & Edlin-White (2009) apud Millen et al. (2010) \\
\hline Equipamentos apropriados as limitações das crianças & Edlin-White (2009) apud Millen et al. (2010) \\
\hline $\begin{array}{c}\text { Facilitar a excelente capacidade de memorização de } \\
\text { cada indivíduo }\end{array}$ & Van Rijn e Stappers (2008) \\
\hline
\end{tabular}

Durante as observações não foi possível observar 5 recomendações encontradas na pesquisa bibliográfica. A primeira se refere ao "Uso dos interesses especiais de cada indivíduo", a qual não foi possível observar pois foram utilizados durante as observações aplicativos que pudessem ser usados com todos os participantes TEA atendendo suas habilidades e não interesses especiais. A recomendação de Dautenhahn (2000), “Generalização”, também não foi possível confirmar pois não houve como identificar se o que foi aprendido pelas crianças com TEA nas observações através dos aplicativos, foi replicado para fora do ambiente da observação. A de Edlin-White (2009) apud Millen et al. (2010), "Elementos competitivos deveriam ser omitidos", não foi confirmada pois sua definição não é especificada no texto, gerando significado ambíguo sobre sua recomendação. Outra recomendação dos mesmos autores, "Equipamentos apropriados as limitações das crianças”, também não foi possível observar pois foi utilizado apenas um tablet durante as observações com as crianças TEA e nenhum dos participantes possuía limitações motoras. A recomendação de Van Rijn e Stappers (2008), "Facilitar a excelente capacidade de memorização de cada indivíduo" não foi possível identificar pois não foi utilizada nenhuma atividade que as crianças necessitassem utilizar a memorização, assim não possibilitando a confirmação desta recomendação.

A Tabela 7 apresenta as recomendações propostas por esta pesquisa e a seguir são colocadas breves descrições.

Tabela 7: Recomendações elaboradas por esta pesquisa.

\begin{tabular}{|c|c|c|}
\hline Recomendação & Observações & Profissionais \\
\hline Apresentar níveis de dificuldade & $\mathrm{X}$ & $\mathrm{X}$ \\
\hline Sons e imagens condizentes com a realidade & $\mathrm{X}$ & $\mathrm{X}$ \\
\hline Uso de recursos visuais/sonoros para incentivos & $\mathrm{X}$ & $\mathrm{X}$ \\
\hline Atenção com recursos sonoros & $\mathrm{X}$ & $\mathrm{X}$ \\
\hline Sequências de passos simples & $\mathrm{X}$ & $\mathrm{X}$ \\
\hline Incentivar o uso da fala & & $\mathrm{X}$ \\
\hline
\end{tabular}

Apresentar níveis de dificuldade: Um software desenvolvido para crianças diagnosticadas com TEA, poderia apresentar níveis de dificuldade. Esses níveis poderiam ser configuráveis por profissionais ou responsáveis das crianças TEA, assim respeitando o tempo de aprendizagem de cada indivíduo TEA. Recomendação sugerida pelos profissionais da clínica como observado nos resultados dos questionários, e também durante as observações. Pode se notar durante a interação com alguns aplicativos que algumas crianças se sentiam entediadas com a monotonia de alguns deles, como relatado na observação do aplicativo TP-Shape.

Sons $\boldsymbol{e}$ imagens condizentes com a realidade: Imagens condizentes com a realidade, de maneira que as crianças TEA consigam reconhecê-las e associá-las ao seu dia-dia. Deve-se 
também tomar cuidado com os sons, para que não haja repetições errôneas por parte das crianças, como observado durante a interação com o aplicativo ABC-Palavras.

Uso de recursos visuais/sonoros para incentivos: Durante a interação dos participantes TEA desta pesquisa com os aplicativos escolhidos para a pesquisa de campo, notou-se que ao interagir com aplicativos que possuíam algum tipo de incentivo ao realizar uma ação correta foi reforçador, levando os participantes a continuarem a atividade. Porém, o que também foi observado é que a inclusão de recursos de recompensas e incentivos deve ser feita com parcimônia. Nas observações realizadas, para algumas crianças estes recursos se mostraram efetivos no seu papel de manter o interesse das crianças no jogo, como o apresentado no aplicativo TP-Shape. Por exemplo, os avatares interagindo com o usuário, como o apresentado no Color Monster também chamaram a atenção das crianças e colaboraram para que elas realizassem as atividades propostas. Porém, também foi observado que muitos estímulos, como os apresentados no jogo Aiello, podem causar um certo desconforto em algumas crianças.

Atenção com recursos sonoros: Nas observações pode-se verificar que a emissão dos sons dos jogos causou reações inesperadas (e acredita-se, não intencionadas pelos(as) designers do jogo). Por exemplo, a preferência por parte de algumas crianças observadas pelo som de indicação de erro sobre o do acerto. As crianças acabavam errando propositalmente, nos jogos TP-Shape e Color Monster, para poder escutar o som agradável aos seus ouvidos. Preocupação também externada nos questionários respondidos pelos(as) profissionais da clínica, como visto na seção 4.1. Este resultado sugere a necessidade de mais pesquisas sobre a relação de crianças com TEA e tipos de sons. Acredita-se que uma pesquisa multidisciplinar com músicos, terapeutas e profissionais da área de Computação poderia trazer muitos benefícios para a interação de crianças TEA com recursos sonoros.

Sequências de passos simples: Muitos passos para realizar um movimento dentro de um jogo podem gerar confusão para as crianças TEA. Elas facilmente se desconcentram, por isso muitos passos na atividade podem fazer com que desistam dela, como observado na interação com aplicativo 123 Color. Ainda de acordo com a observação do aplicativo 123 Color se notou que a cada distração das crianças o(a) profissional tinha que explicar novamente os passos para realizar a atividade, pois o jogo continha uma maior sequência de passos do que os outros.

Incentivar o uso da fala: Uma das áreas de prejuízos que pode ser afetada em uma criança com TEA é a comunicação, podendo variar da ausência ao atraso na fala. Softwares que exijam respostas verbais podem servir com uma ferramenta auxiliar no desenvolvimento da comunicação, como sugerido pelos(as) profissionais que responderam os questionários desta pesquisa.

\section{Conclusão}

Este artigo procurou investigar como crianças diagnosticadas com TEA interagem com tecnologias, buscando revisar e sugerir recomendações que desenvolvedores de software possam utilizar.

Primeiramente um breve estudo sobre o TEA foi realizado para o conhecimento do transtorno e das características apresentadas por pessoas diagnosticadas. Após o estudo e compreensão sobre o TEA, uma revisão bibliográfica foi realizada para entender e investigar a relação dos indivíduos TEA com a tecnologia. Também trabalhos que sugerem recomendações para o desenvolvimento de softwares para indivíduos diagnosticados com TEA foram revisados. Nesse estudo pode-se observar que crianças com TEA gostam de tecnologia como qualquer outra criança, e que o uso de computadores e tecnologias realmente demonstram efeitos benéficos e positivos sobre elas. Conheceu-se plataformas, jogos e dispositivos desenvolvidos para o uso com 
o público TEA e a partir da análise dessas ferramentas os(as) autores(as) sugeriram recomendações para o desenvolvimento de softwares ou hardwares para indivíduos do público em questão.

O que foi notado no decorrer desta pesquisa é que embora, de modo geral, a tecnologia tenha sido atrativa para as crianças com TEA, isto não impede a ocorrência de distrações durante a interação. Além disto, embora atraente, o uso de recursos computacionais durante atividades educacionais para crianças TEA requer não apenas um cuidadoso processo de desenvolvimento de tais recursos, mas também requer especial atenção nos processos de escolha e configuração dos aplicativos e jogos.

Durante a pesquisa de campo foi possível observar 12 recomendações encontradas na pesquisa bibliográfica para o desenvolvimento de artefatos tecnológicos para crianças com TEA, e com a análise da pesquisa de campo foi possível contribuir com 6 novas recomendações. Apenas 5 recomendações encontradas na literatura não foram possíveis de observar. Embora, algumas recomendações encontradas na literatura tenham sido propostas a partir de brinquedos desenvolvidos para crianças TEA (Van Rijn \& Stappers, 2008; Dautenhahn, 2000), estas puderam ser observadas na interação com outros artefatos tecnológicos como os aplicativos educacionais usados nesta pesquisa.

As recomendações divulgadas por Britto e Pizzolato (2018) em seu website ${ }^{16}$ não foram possíveis serem observadas e analisadas durante a interação com indivíduos TEA, pois as observações aconteceram anteriormente a essa publicação. Porém, pode-se notar que as recomendações compiladas pelos(as) autores(as) complementam as recomendações desta pesquisa, como por exemplo, permitir a customização de cores, tamanhos de texto e fontes, além da personalização de funcionalidades. A linguagem visual e textual simples fornecendo instruções e orientações claras sobre as tarefas, assim como imagens, ícones e menus compatíveis com o mundo real, e etc.

Mesmo que existam recomendações para o desenvolvimento de softwares para crianças com TEA, as interações observadas nesta pesquisa indicam que tanto os jogos desenvolvidos quanto os não desenvolvidos para o público TEA podem atender as necessidades dos(as) profissionais que trabalham nesta área, sendo assim as recomendações revisadas da literatura e sugeridas através da pesquisa de campo também poderiam ser aplicadas durante o desenvolvimento de softwares dirigidos ao público em geral.

Algumas dificuldades foram encontradas durante a realização da pesquisa. Por exemplo, o tablet utilizado pela clínica tem um sistema operacional antigo, e muitos aplicativos desenvolvidos especificamente para o público com TEA solicitavam uma versão mais recente do sistema. Desta forma, não puderam ser instalados no dispositivo limitando as possibilidades de escolha dos jogos que poderiam ser utilizados nas observações. Como consequência, um maior número de jogos não desenvolvidos especificamente para o público TEA foi utilizado.

A participação voluntária dos participantes não garantia a participação das crianças em todos os dias das observações. Em apenas um dos quatro dias de observação todas as crianças estavam presentes, assim como no dia dos testes pilotos. Somente as crianças A (8 anos, nível 2 de TEA) e B (6 anos, nível 2 de TEA) participaram de todas as observações. A ausência das crianças impede que outras análises comparativas possam ser feitas sobre a interação com os jogos.

O acompanhamento de profissionais mediando a interação das crianças com a ferramenta utilizada foi/é imprescindível para o sucesso das observações. Os(as) profissionais auxiliaram as

\footnotetext{
${ }^{16}$ http://talitapagani.com/gaia/
} 
crianças a manter o foco e a incentivá-los a continuar as atividades. Além disto, a presença de profissionais capacitados(as) e especializados(as) em TEA proporcionam um canal de comunicação com a criança que possivelmente não aconteceria espontaneamente entre a observadora e o(a) participante do estudo de caso, reforçando as considerações de Ribeiro et al. (2013).

A singularidade de cada interação indica a riqueza de resultados que podem ser descobertos em cada observação. Consequentemente, sugere a necessidade de um maior número de observações para que se possa compreender melhor a relação de pessoas com TEA e suas interações com a tecnologia.

Com este trabalho espera-se contribuir com os grandes desafios de pesquisa em Interação Humano-Computador do GranDIHC, (Baranauskas et al., 2014), produzindo mais conhecimento sobre acessibilidade para crianças diagnosticadas com TEA no Brasil. Também se espera que as recomendações possam auxiliar desenvolvedores a construir softwares condizentes com as características desse grupo quando sessões de design participativo não forem possíveis de serem realizadas, lembrando que estudos nesta área ainda precisam ser realizados para que se possa envolver a maior quantidade de indivíduos com TEA nestas sessões.

Como trabalhos futuros sugere-se a aplicação das recomendações sugeridas neste trabalho no desenvolvimento de aplicativos educacionais para crianças com TEA. E também a confirmação ou não delas em outros artefatos tecnológicos. Embora as recomendações sejam úteis para o desenvolvimento de artefatos tecnológicos para crianças com TEA, também se sugere a elaboração de mais pesquisas sobre como envolver pessoas diagnosticadas com TEA de diferentes idades, níveis de TEA, e características em sessões de design participativo. E por último uma retificação das recomendações elaboradas nesta pesquisa com pessoas TEA de outras idades, níveis e características.

\section{Referências}

American Psychiatric Association \& Others. (2014). Manual diagnóstico e Estatístico de Transtornos Mentais (5th ed., text rev.). Artmed Editora. [GS SEARCH]

Baranauskas, M. C., Souza, C. S., \& Pereira, R. (2014). I GranDIHC-Br - Grandes Desafios de Pesquisa em Interação Humano-Computador no Brasil. Relatório Técnico. Comissão Especial de Interação Humano-Computador (CEIHC) da Sociedade Brasileira de Computação (SBC) (2014). doi: http://doi.org/10.13140/2.1.3651.9201

Barry, M., Kehoe, A., \& Pitt, I. (2008). Usability evaluation of educational game software for children with autism. World Conference on Educational Media and Technology. 1366-1370. Retrieved from: https://www.learntechlib.org/noaccess/28561/ [GS SEARCH]

Barry, M., \& Pitt, I. (2006). Interaction design: a multidimensional approach for learners with autism. Conference on Interaction design and children. ACM, 33-36. doi: http://doi.org/10.1145/1139073.1139086 [GS SEARCH]

Britto, T. C. P. \& Pizzolato, E. B. (2018). GAIA: a proposal guide of recommendations of Web interfaces accessibility with focus on Autism aspects (GAIA: uma proposta de um guia de recomendações de acessibilidade de interfaces Web com foco em aspectos do Autismo). Brazilian Journal of Computers in Education (Revista Brasileira de Informática na Educação - RBIE), 26(2), 102-123. doi: http://dx.doi.org/10.5753/rbie.2018.26.02.102 [GS SEARCH]

Cunha, R. M. (2011). Desenvolvimento e avaliação de um jogo de computador para ensino de vocabulário para crianças com autismo. PUC-Rio. Retrieved from: https://www.maxwell.vrac.puc-rio.br/Busca_etds.php?strSecao=resultado\&nrSeq=19646@1 [GS SEARCH] 
Dautenhahn, K. (2000). Design issues on interactive environments for children with autism. 3rd International Conference on Disability, Virtual Reality and Associated Technologies University of Reading. Retrieved from: https://uhra.herts.ac.uk/handle/2299/1944 [GS $\underline{\text { SEARCH] }}$

Farias, E. B., Silva, L.W.C., \& Cunha, M.X.C. (2014). ABC AUTISMO: Um aplicativo móvel para auxiliar na alfabetização de crianças com autismo baseado no Programa TEACCH. X Simpósio Brasileiro de Sistemas de Informação (2014), 458-469. Retrieved from: http://www.lbd.dcc.ufmg.br/colecoes/sbsi/2014/0039.pdf [GS SEARCH]

Goldsmith, T. R. \& LeBlanc, L. A. (2004). Use of technology in interventions for children with autism. Journal of Early and Intensive Behavior Intervention, 1(2):166-178. doi: http://dx.doi.org/10.1037/h0100287 [GS SEARCH]

Mello, A., M., S. (2001). Autismo: guia prático. Brasília: Corde. Retrieved from: http://www.autismo.org.br/site/images/Downloads/7guia\%20pratico.pdf [GS SEARCH]

Millen, L., Edlin-White, R., \& Cobb, S. (2010). The development of educational collaborative virtual environments for children with autism. 5th Cambridge Workshop on Universal Access and Assistive Technology. Cambridge. V1, 7. Retrieved from: https://www.researchgate.net/publication/266874791_The_Development_of_Educational_C ollaborative_Virtual_Environments_for_Children_with_Autism [GS SEARCH]

Neto, A., Rufino, H., Nakamoto, P., Palis, R., \& Beira, D. (2017). Cotidiano: um software para auxiliar crianças autistas em suas atividades diárias. Simpósio Brasileiro de Informática na Educação-SBIE, Vol. 28. 404. doi: http://dx.doi.org/10.5753/cbie.sbie.2017.404 [GS SEARCH]

Pantoja, J., Sousa, A., \& de Araújo Júnior, R. M. (2018). Alfa autista: uma aplicação mobile para o auxílio na alfabetização do autista através de método fônico. Um estudo de caso na APAEMarabá. Simpósio Brasileiro de Informática na Educação-SBIE, Vol. 29. 1873. Retrieved from: http://br-ie.org/pub/index.php/sbie/article/view/8177 [GS SEARCH]

Piconi, A. C., \& Tanaka, E. H. (2003). A construção de histórias em quadrinhos eletrônicas por alunos autistas. Simpósio Brasileiro de Informática na Educação-SBIE, Vol. 1. 385-394. doi: http://dx.doi.org/10.5753/cbie.sbie.2018.1873 [GS SEARCH]

Putnam, C. \& Chong, L. (2008). Software and technologies designed for people with autism: what do users want?. 10th international ACM SIGACCESS conference on Computers and accessibility. 3-10. doi: http://doi.org/10.1145/1414471.1414475 [GS SEARCH]

Ribeiro, P. C., Braz P., Silva G. F. M., \& Raposo A. (2013). ComFiM: Um Jogo Colaborativo para Estimular a Comunicação de Crianças com Autismo. X Brazilian Symposium in Collaborative Systems. Sociedade Brasileira de Computação, 72. Retrieved from: https://dl.acm.org/citation.cfm?id=2542522\&dl=ACM\&coll=DL\&CFID=841796750\&CFT OKEN=40231395 [GS SEARCH]

Van Rijn, H., \& Stappers, P. J. (2008). The puzzling life of autistic toddlers: design guidelines from the LINKX project. Advances in Human-Computer Interaction. doi: http://dx.doi.org/10.1155/2008/639435 [GS SEARCH] 